\title{
Recent Advances in the Synthesis of Perimidines and their Applications
}

\author{
Nusrat Sahiba ${ }^{1} \cdot$ Shikha Agarwal ${ }^{1}$
}

Received: 18 April 2020 / Accepted: 25 July 2020 / Published online: 10 August 2020

(c) Springer Nature Switzerland AG 2020

\begin{abstract}
Perimidines are versatile scaffolds and a fascinating class of $N$-heterocycles that have evolved significantly in recent years due to their immense applications in life sciences, medical sciences, and industrial chemistry. Their ability of molecular interaction with different proteins, complex formation with metals, and distinct behavior in various ranges of light makes them more appealing and challenging for future scientists. Various novel technologies have been developed for the selective synthesis of perimidines and their conjugated derivatives. These methods extend to the preparation of different bioactive and industrially applicable molecules. This review aims to present the most recent advancements in perimidine synthesis under varied conditions like MW radiation, ultrasound, and grinding using different catalysts such as ionic liquids, acid, metal, and nanocatalyst and also under green environments like catalyst and solvent-free synthesis. The applications of perimidine derivatives in drug discovery, polymer chemistry, photo sensors, dye industries, and catalytic activity in organic synthesis are discussed in this survey. This article is expected to be a systematic, authoritative, and critical review on the chemistry of perimidines that compiles most of the state-of-art innovation in this area.
\end{abstract}

Shikha Agarwal

shikhaagarwal@mlsu.ac.in

Nusrat Sahiba

sahibanusrat786@gmail.com

1 Synthetic Organic Chemistry Laboratory, Department of Chemistry, MLSU, Udaipur 313001, India 


\section{Graphic Abstract}

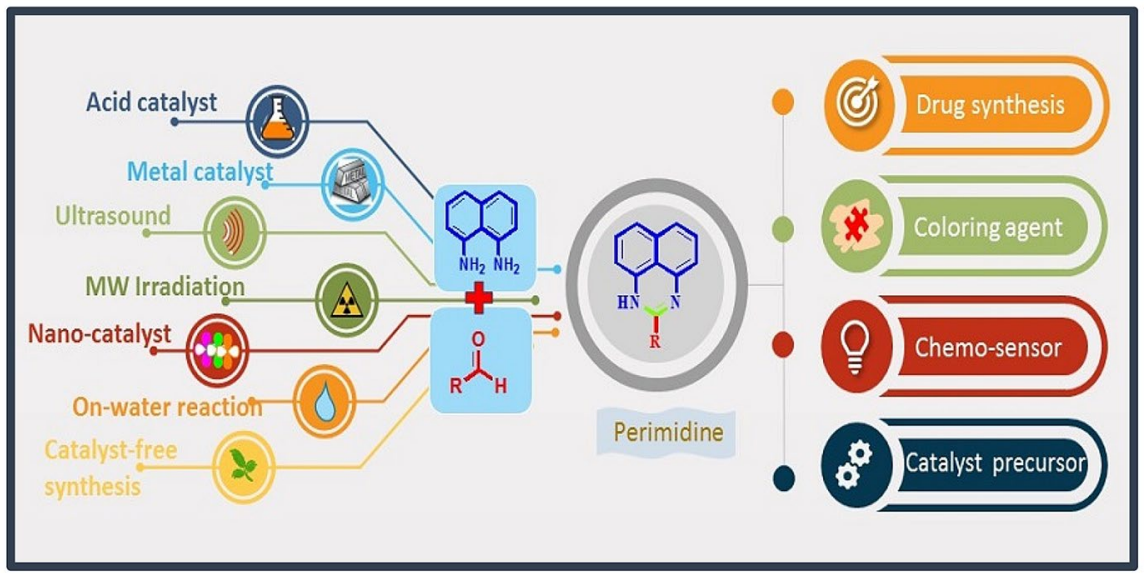

Keywords $N$-heterocycles $\cdot$ Perimidines $\cdot$ Synthesis $\cdot$ Catalysis $\cdot$ Biologic activity

$\begin{array}{ll}\text { Abbreviations } \\ \text { CRF } & \text { Corticotropin-releasing factor } \\ \text { MW } & \text { Microwave } \\ \text { NDA } & \text { 1,8-Naphthalenediamine } \\ \text { HPA } & \text { Heteropolyacids } \\ \text { MCM } & \text { Mobil composition of matter } \\ \text { HBOB } & \text { Bis(oxalato) boric acid } \\ \text { PTSA } & \text { P-toluene sulfonic acid } \\ \text { CMK } & \text { Nanoporous carbon } \\ \text { DCM } & \text { Dichloromethane } \\ \text { THF } & \text { Tetrahydrofuran } \\ \beta \text {-CD } & \beta \text {-Cyclodextrin } \\ \text { RT } & \text { Room temperature } \\ \text { DDQ } & \text { 2,3-Dichloro-5,6-dicyano-1,4-benzoquinone } \\ \text { DMSO } & \text { Di-methyl sulphoxide } \\ \text { PEG } & \text { Polyethylene glycol } \\ \text { MWI } & \text { Microwave irradiations } \\ \text { KB } & \text { Kilobase of DNA/RNA } \\ \text { MDR } & \text { Multi-drug resistance } \\ \text { MCF-7 } & \text { Breast cancer cell lines } \\ \text { Caco-2 } & \text { Colon cancer cell lines } \\ \text { Hep-2 } & \text { Laryngeal carcinoma cancer cell lines } \\ \text { WI-38 } & \text { Fibroblast cell lines } \\ \text { IC50 Value } & \text { Half-maximal inhibitory concentration } \\ \text { SAR } & \text { Structure-activity relationship } \\ & \end{array}$


UACC-62 A panel of cancer cell lines

TK-10 Renal cancer cell lines

Ache Acetylcholinesterase

LPS Lipopolysaccharides

IL Interleukin

TNF Tumor necrosis factor

COX-2 Cyclooxygenases

T47D Breast cancer cell lines

H-522 Lung cancer cell lines

Hepg2 Liver cancer cell lines

HCT-15 Colon cancer cell lines

PA-1 Ovary cancer cell lines

HL-60 Leukemia cancer cell lines

EW Electron withdrawing group

HK Heterocyclic ketene aminals

HOMO Highest occupied molecular orbital

LUMO Lowest unoccupied molecular orbital

DFT Density functional theory

UV-V Ultraviolet-visible

\section{Introduction}

Nitrogen-containing heterocycles are the key-frame work of many essential natural and synthetic products of our everyday lives [1-5]. A wide range of $N$-heterocycles is present in nature in living cells [6], alkaloids, hormones [7], and amino acids, and therefore constitutes a large fraction of medicinal and industrial chemistry. Perimidine and $1 H$-benzo [d,e] quinazolines are fascinating tricyclic moieties bearing unique properties, i.e., presence of both $\pi$-excessive and $\pi$-deficient arrangement. Perimidines and peri-naphtho-fused pyrimidine systems also serve as an interesting class of saturated $N$-heterocycles due to the existence of a lone pair of nitrogen atoms that transfer their electron density to naphthalene ring from fused heterocyclic ring and increase the possibility of future reaction chemistry via both electrophilic and nucleophilic reactions (Scheme 1). Perimidine was first perceived in 1874 by de Aguiar [8] and an extensive study was demonstrated by Sachs in 1909 [9]. Its electronic properties are responsible for its role in various industries including medicine and agriculture chemistry.

Scheme 1 Perimidine molecule and charge distribution

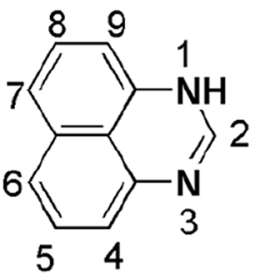


Scheme 2 Some synthesized biological active perimidines

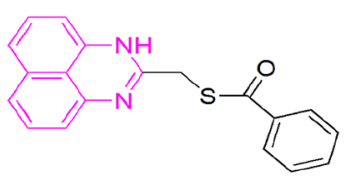

Anti-inflammatory

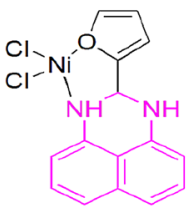

Antimicrobial

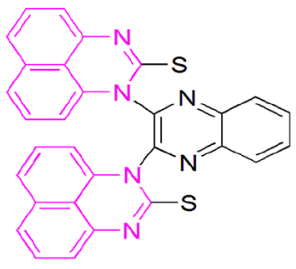

Antimicrobial

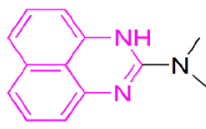

Cytotoxic

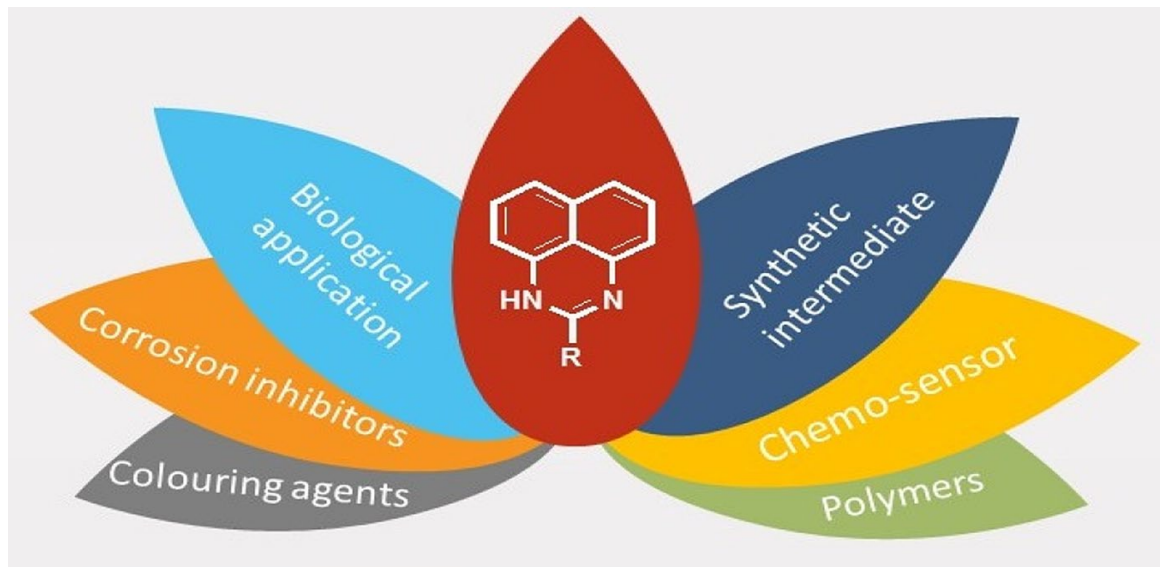

Fig. 1 Application of perimidines in diverse areas

It is used as a coloring agent and dye intermediate in fibers and plastic synthesis, carbene ligand generation, and corrosion inhibitors [10-12]. It also works as a potent drug against various diseases and behaves as antitumor, antimicrobial, antifungal, antiulcer, antioxidant, anti-inflammatory agent, and corticotropin-releasing factor (CRF) receptor-selective antagonists [13-16] etc. (Scheme 2).

Furthermore, its derivatives behave as fluorescent chemo-sensors and stoppers for supramolecules, generate photochemic memory devices, intermediate in organic synthesis, and also display DNA-binding properties [17-24] etc. (Fig. 1). Due to its unique electronic features and immense applications in diverse areas, researchers are keenly interested in its environmental benign synthesis. This interest has led to the design of various methodologies of perimidines and their composite synthesis. To date, a large number of perimidines has been designed under different conditions and their applications in different fields 
have also been examined. In light of their tremendous progress and above discussion, we believe that a timely critical discussion on a particular topic may increase the possibilities of future development [25-30]. The first review article on perimidine moiety was published in [31] and later on by Pozharskii and Dal'nikovskay in [32]. In the last four decades, there has been a huge upsurge in the synthesis and applications of perimidines and no detailed discussions have been done in this emerging field to date. In lieu of this, we have critically reviewed the state-of-art evolution on perimidines and their derivatives with multifarious applications. This article is not a comprehensive study, but a systematic review including several aspects of synthesis and applications of perimidines from 1981 to now. The first section includes the synthesis of perimidines under different conditions, viz., green solvents, temperature, and catalyst etc., using various synthetic techniques like conventional heating, stirring, grinding, microwave (MW), and ultrasound radiation with their unique advantages and limitations. The second part includes the applications of perimidines in medicinal, synthetic chemistry, and other areas of life. The last portion covers the challenges and critical discussion of perimidines in terms of their structure, synthesis, medical, structure-activity relationship, and other fields to discover the next-generation eco-friendly techniques for society and humanity. This review article will give new directions for greener and more sustainable synthesis of perimidine scaffolds in every aspect of life inclusive of agriculture, medicine, materials, electronics, and polymers.

\section{Chemistry of Perimidines}

Perimidines and the peri-naphtho-fused pyrimidine system is a new and rapidly growing area of pure and applied chemistry, especially from 2010 [33-36]. In this remarkable advancement, vast development has occurred in the field of structure [37-41], synthesis [42-50], spectral studies [51], bonding with different motifs and ligands [52-57], and their complex reactivity in various fields, etc. [58-67]. So, most of the literature has been covered to give complete knowledge about perimidine motifs.

Perimidine is a heterocycle containing two nitrogen atoms at the first and third positions that increase the delocalization of pi-electrons in tricycles and enhances the potential of different synthesis. Scheme 1 shows the structure and uneven charge distribution in perimidines which is responsible for its synthetic behavior. Perimidine shows oxidation at the 4th and 9th positions due to high electron density and reduction at $\mathrm{N}$-alkylated positions. The heteroaromatic ring shows nucleophilic reactions and the naphthalene ring gives electrophilic substitution reactions like acylation, halogenation, sulphonation, etc. $\mathrm{N}$-Alkylated perimidines form quaternary salts via condensation with acylating molecules at the 6 and 7 positions and produce perimidin-2-ones via hydroxylation. Perimidines form colored compounds due to their pi-electron donation to the weak acids. 
Scheme 3 General reaction for perimidine synthesis
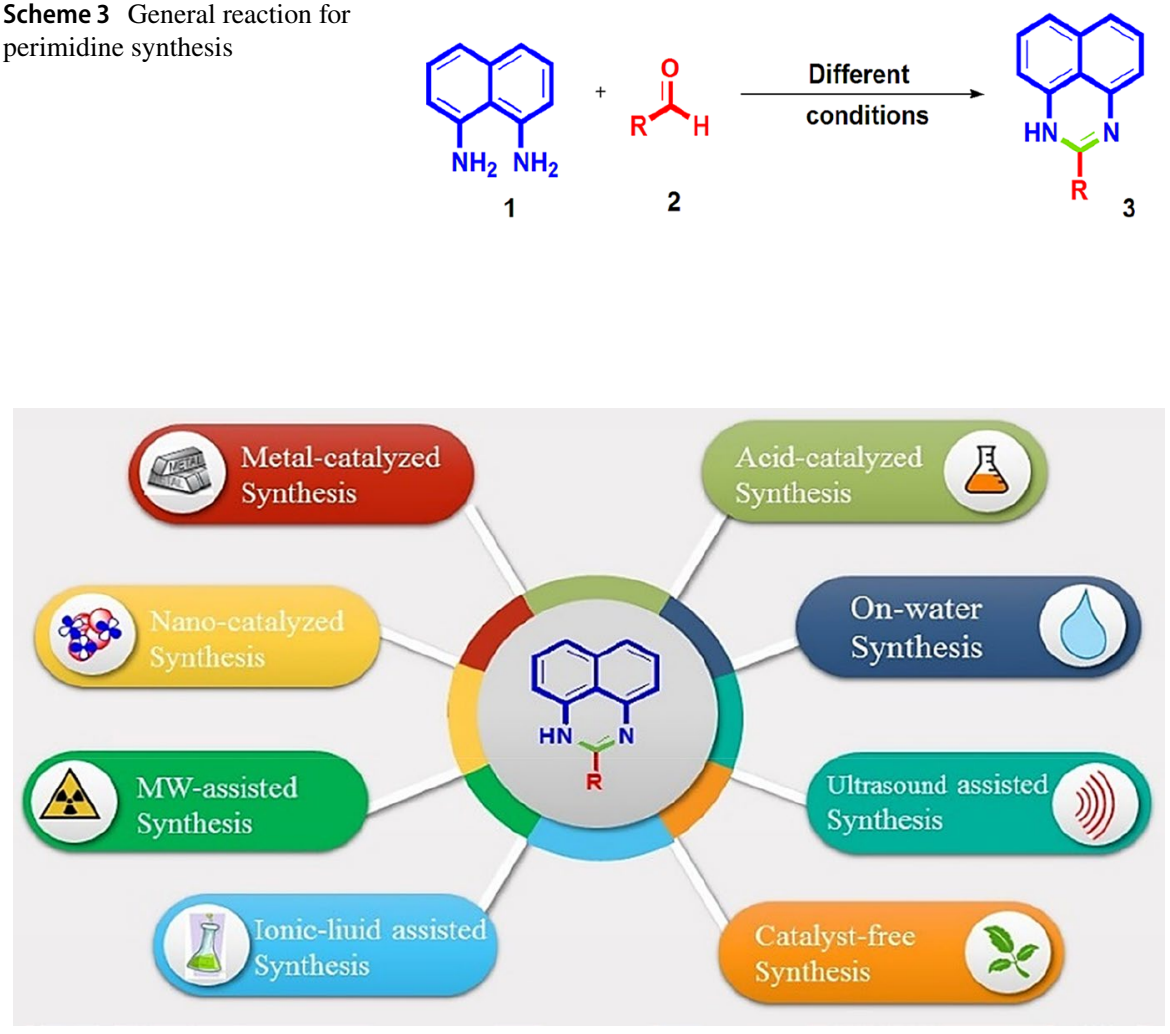

Fig. 2 Various approaches of perimidine synthesis

\section{General Synthesis of Perimidines}

Perimidine nucleus contains two nitrogen atoms in 1,3 position of the six-membered ring fused with the naphthalene ring. From the structural outcome, the idea about the cyclization of di-amino group with activated carbonyl group gives a suitable match. Most of the reported methods involve condensation of 1,8-naphthalenediamine (NDA) (1) and its derivatives with carbonyl compounds (2) to produce perimidines (3) (Scheme 3). Various conditions are applied using acid catalyst, metal catalyst, nanocatalyst, and catalyst-free approaches (Fig. 2).

The mechanistic pathway for the synthesis of perimidines is depicted in Scheme 4. Initially, the carbonyl carbon (2) get activated in the presence of either catalyst or solvent. This activation facilitates the reaction between the carbonyl group and amino group of NDA (1) and forms a Schiff base imine (i) with removal of a water molecule and further another activated amino group displays nucleophilic attack on imine group and affords cyclic intermediate (ii). Finally, 1,3-proton transfer produces corresponding perimidine derivatives (3). 


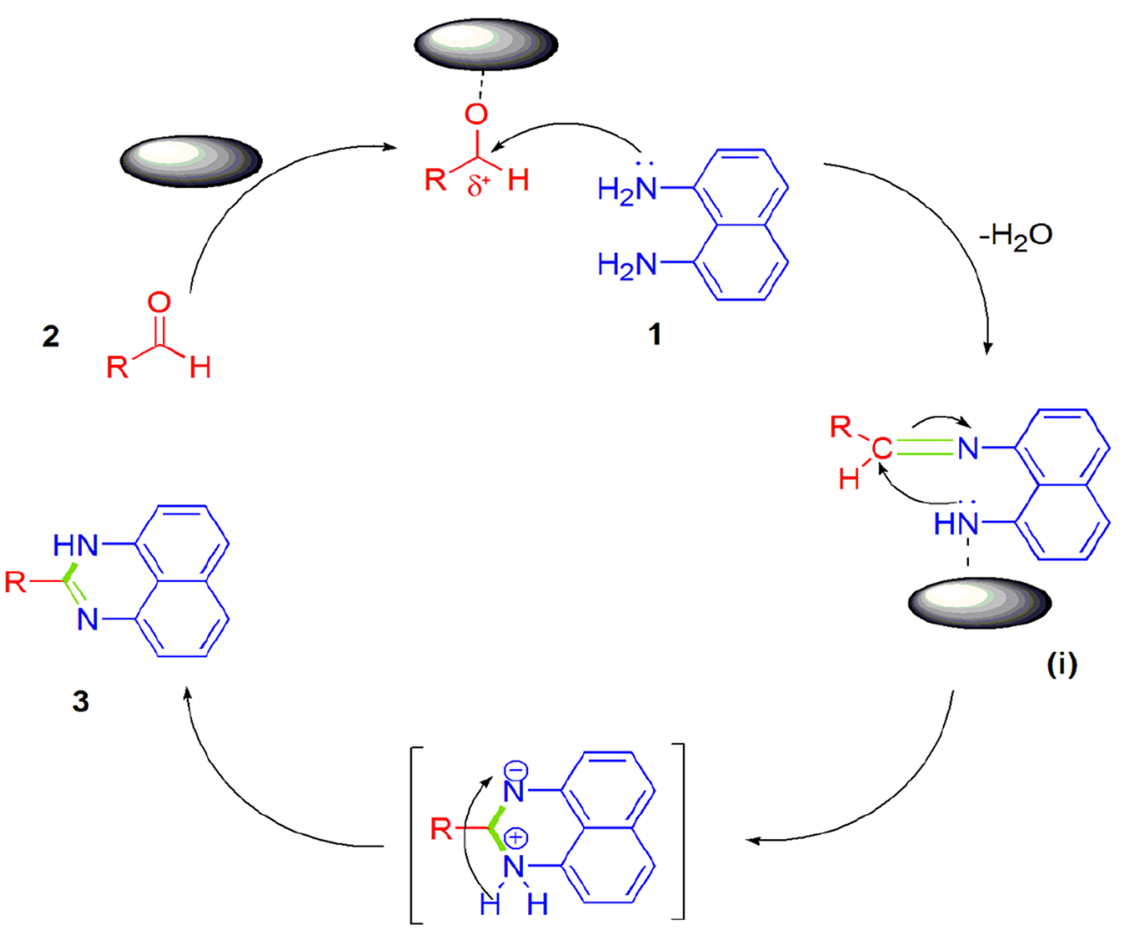

(ii)

Scheme 4 A possible mechanism for the synthesis of perimidine

\section{Perimidine Synthesis Under Different Conditions}

\subsection{Acid-Catalyzed Synthesis}

Presently, many organic transformations are carried out using acid catalysts that give easy accessibility for a particular synthesis. Mild reaction conditions, versatility, and selective synthesis are the important features of this catalytic group $[68,69]$.

In 2010, Zendehdel et al. [70] synthesized perimidines using a series of hybrid heteropolyacids (HPA) by refluxing 1,8-naphthalenediamine (NDA) and aromatic aldehydes in ethanol for $5 \mathrm{~h}$ at $80{ }^{\circ} \mathrm{C}$. The order of the catalytic efficiency is as follows: HPA/NaY $>\mathrm{HPA} / \mathrm{NaY} / \mathrm{MCM}-41>\mathrm{NaY}>\mathrm{HPA}>\mathrm{MCM}-41$. According to this pattern, the authors evaluated that high acidic strength, more heterogeneous characteristics, and high dispersion of HPA increased protonic sites on the catalyst surface, and as a result, HPA/NaY catalyst exhibited high yields (Scheme 5, Method 1). A simple, reliable, and highly efficient protocol for the synthesis of substituted 2,3-dihydro- $1 H$-perimidine from NDA and ketones using bis(oxalato) boric acid (HBOB) in high yields (70-95\%) was reported by Phadtare and 


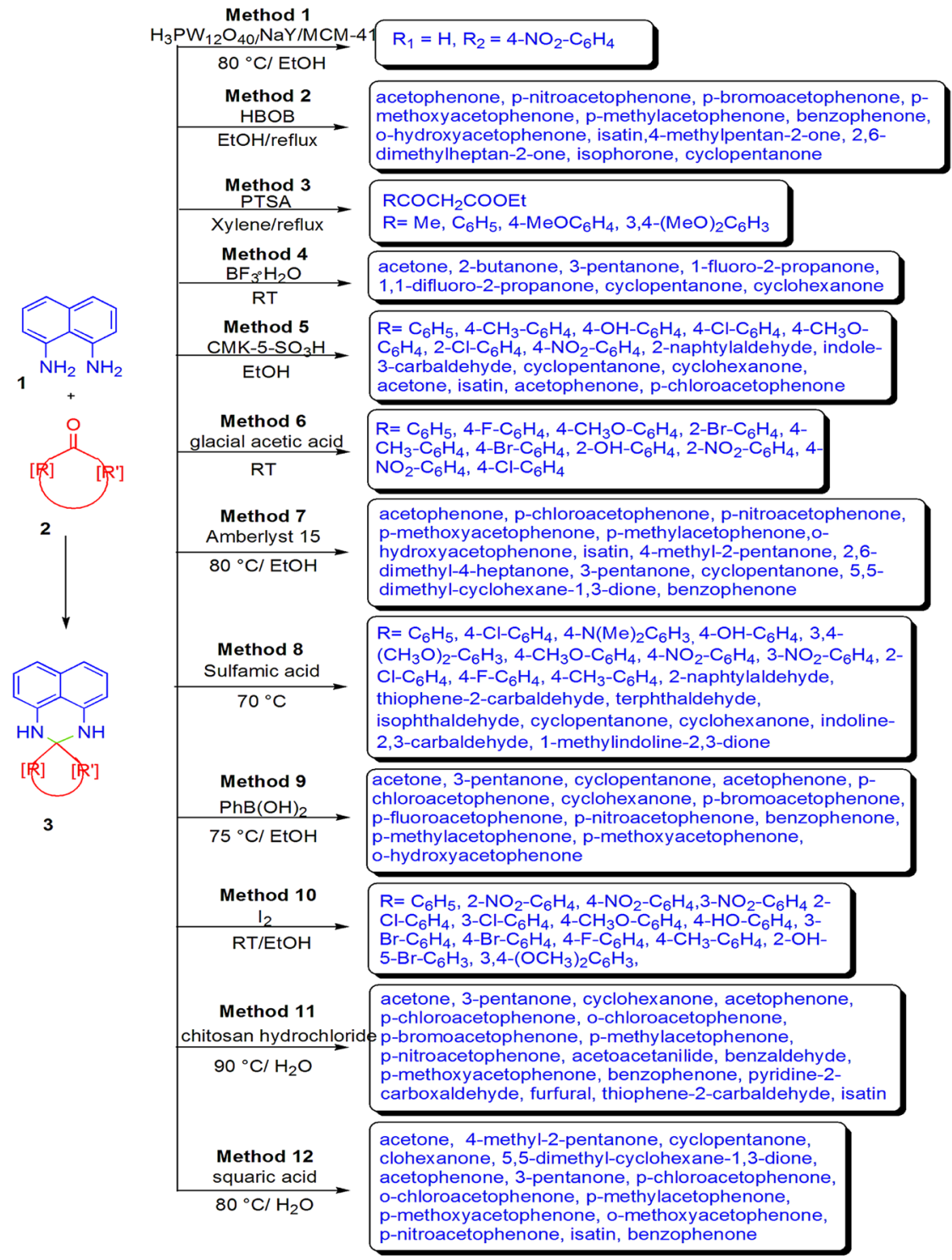

Scheme 5 Acid-catalyzed perimidine synthesis in different conditions

co-authors [71]. Authors also studied the optimized conditions and concluded that refluxing with $10 \mathrm{~mol} \% \mathrm{HBOB}$ in ethanol displayed excellent catalytic efficiency. The use of green solvent, mild conditions, recoverable catalyst, simple workup, and broad substrate scope made this procedure eco-friendly (Scheme 5, Method 2). 
Koca and coworkers [72] designed two novel and efficient routes for the synthesis of perimidine derivatives using acid catalyst. In the first method, NDA and heterocyclic ketene were refluxed with PTSA and xylene, and further reacted with $\mathrm{COCl}_{2}$ in $\mathrm{MeCN}$ for $1 \mathrm{~h}$ to produce substituted perimidines. In the second method, NDA was refluxed with 2-alkoxycarbonylmethylene substituted furan-3-ones in methanol and corresponding perimidines were produced in good yields (72-79\%) (Scheme 5, Method 3). Prakash and companions [73] disclosed a simple, one-pot and highyielding protocol for the synthesis of perimidine derivatives using $\mathrm{BF}_{3} \cdot \mathrm{H}_{2} \mathrm{O} \mathrm{Br} ø$ sted acid as an effective catalyst and solvent from the cyclocondensation of NDA and various ketones in ethanol at ambient temperature via eco-benign pathways (Scheme 5, Method 4).

Alinezhad and Zare [74] examined sulfonated nanoporous carbon (CMK-5$\mathrm{SO}_{3} \mathrm{H}$ ) as a new, efficient catalyst for the synthesis of perimidines from NDA and carbonyl compounds such as aldehyde and ketone using ethanol at room temperature. For comparative study, the authors applied different solvents, viz., 1,4-dioxane, acetonitrile, DCM, $\mathrm{H}_{2} \mathrm{O}$, THF, and $\mathrm{EtOH}$ with variation in the amount of catalyst. However, EtOH with $1 \mathrm{~mol} \%$ catalyst was found to be the most appropriate in terms of yields. Simple procedure, use of aliphatic, aromatic and heterocyclic substrate, environmentally benign conditions, shorter reaction times, high atom economy, recyclability, and reusability of catalyst are the remarkable advantages of this protocol (Scheme 5, Method 5). Azeez and co-authors [75] explored a direct and efficient preparation of perimidines derivatives and tested them for antibacterial activity against Gram-negative and Gram-positive bacteria $S$. aureus and Gram-negative bacteria $E$. coli using agar diffusion method. Cyclocondensation of NDA with different aldehydes in glacial acetic acid at room temperature gave appropriate perimidines in moderate to excellent yields. Among all the synthesized compounds, most of the derivatives were not active against $S$. aureus, while they effectively worked against E. coli as compared to a reference drug, gentamycin (Scheme 5, Method 6).

Patil and Shankarling [76] developed an eco-benign, efficient pathway for perimidine synthesis using Amberlyst 15 as a metal-free recyclable and reusable catalyst. A broad range of carbonyl compounds like aliphatic, aromatic, and alicyclic ketones were stirred with NDA in ethanol at $80{ }^{\circ} \mathrm{C}$ to obtain good yields. For the feasibility of reaction, the authors applied variation in different parameters like catalyst, viz., sulfated zirconia, Indion-130, Amberlite-120, Amberlyst-15, and catalyst-free synthesis and solvents, viz., 1,3-dioxane, acetonitrile, DES, DCM, $\mathrm{H}_{2} \mathrm{O}, \mathrm{EtOH}$, and solvent-free synthesis. It was found that Amberlyst 15 worked well with EtOH at 80 ${ }^{\circ} \mathrm{C}$ for perimidine synthesis in high yields. This protocol was not preferred for sterically hindered ketones under ambient reaction conditions (Scheme 5, Method 7). Bodaghifard and Ahadi [77] reported a novel, eco-friendly and simple synthesis of perimidines from NDA and aldehydes at $70{ }^{\circ} \mathrm{C}$ under solvent-free conditions using sulfamic acid as a recyclable catalyst. The authors screened the effect of varied temperature (RT, $50{ }^{\circ} \mathrm{C}$ and $70{ }^{\circ} \mathrm{C}$ ) and solvents $\left(\mathrm{CHCl}_{3}, \mathrm{CH}_{3} \mathrm{CN}, \mathrm{H}_{2} \mathrm{O}, \mathrm{H}_{2} \mathrm{O} / \mathrm{EtOH}\right.$ and toluene) on the reaction (Scheme 5, Method 8).

Patil et al. [78] investigated a simple, reliable, and one-pot synthesis of 2,3-dihydro- $1 H$-perimidines from the condensation of various ketones with NDA in the presence of phenyl boronic acid as Lewis acid catalyst in ethanol at $75{ }^{\circ} \mathrm{C}$ with excellent 
yields. Here, shorter reaction time, mild reaction conditions, easy handling of catalyst, simple workup, and high atom economy are the additional merits of this procedure (Scheme 5, Method 9). Mobinikhaledi et al. [79] investigated a facile, green, and eco-friendly route for the synthesis of substituted perimidines in moderate to excellent yields from NDA and aldehydes using molecular iodine and evaluated them as antibacterial agents against $S$. aureus and E. coli via by agar disk diffusion method. To examine the effect of various parameters, the authors carried out this reaction in different solvents like $\mathrm{EtOH}, \mathrm{MeOH}, \mathrm{CH}_{3} \mathrm{CN}$, DMSO, and DMF in variation with a catalytic amount of molecular iodine at room temperature. All the synthesized derivatives have bactericidal properties against both tested strains. Shorter reaction time, use of mild Lewis acid catalyst, green solvent, ambient conditions, and high biologic potency are the additional features of this synthesis (Scheme 5, Method 10).

Recently, an eco-friendly one-pot protocol has been reported by Shelke and companions [80] using a biopolymer-based chitosan hydrochloride as recyclable and reusable catalyst to obtain perimidine derivatives through NDA and different ketones using water as a green solvent at $90{ }^{\circ} \mathrm{C}$ in moderate to high yields. This method includes several advantages as compared to previous methods such as easy workup, use of biodegradable catalyst, low amount of catalyst, and high green matrix values like high atom economy (93.52\%), high eco-score (80), high reaction mass efficiency (96\%), and low E-factor (0.041) (Scheme 5, Method 11).

Khopkar et al. [81] reported an efficient catalyst, squaric acid, for the synthesis of perimidines from NDA and ketone in water at $80{ }^{\circ} \mathrm{C}$. Squaric acid is a green dibasic organocatalyst possessing high selectivity, water solubility, and reusability. The authors studied the optimization conditions using various amounts of catalyst loading $(2.5,5,7.5,10,15 \mathrm{~mol} \%)$ and solvents (water, ethanol, acetonitrile, THF, DMF, toluene, and DCM) along with variation in temperature (RT, 50, 70,80, $100{ }^{\circ} \mathrm{C}$ ). Use of $10 \mathrm{~mol} \%$ of catalyst in water displayed the best results in respect of yields. This protocol has remarkable features like being eco-benign, sustainable, high yielding, easy workup, use of green solvents and catalyst, any reusability of catalyst up to four runs (Scheme 5, Method 12).

The acid-catalyzed synthesis of perimidines in diverse conditions with different substituents is illustrated in Scheme 5 and their comparative study is given in Table 1.

\subsection{Metal-Catalyzed Synthesis}

A variety of heteroatom containing catalyst is an efficient, fast, and versatile tool in organic synthesis due to its special properties to develop multiple substituted complicated molecules. Metal catalysts are abundant, easy to prepare, and inexpensive. Organometallic reagents play a significant role in catalysis [82, 83].

In 2007, Zhang et al. [84] investigated a feasible approach for the synthesis of perimidine using ruthenium(III) chloride as a catalyst via cyclocondensation and Schiff base generation involving NDA and various ketones with ethanol at $40{ }^{\circ} \mathrm{C}$ in excellent yields. The authors also evaluated the generality of 


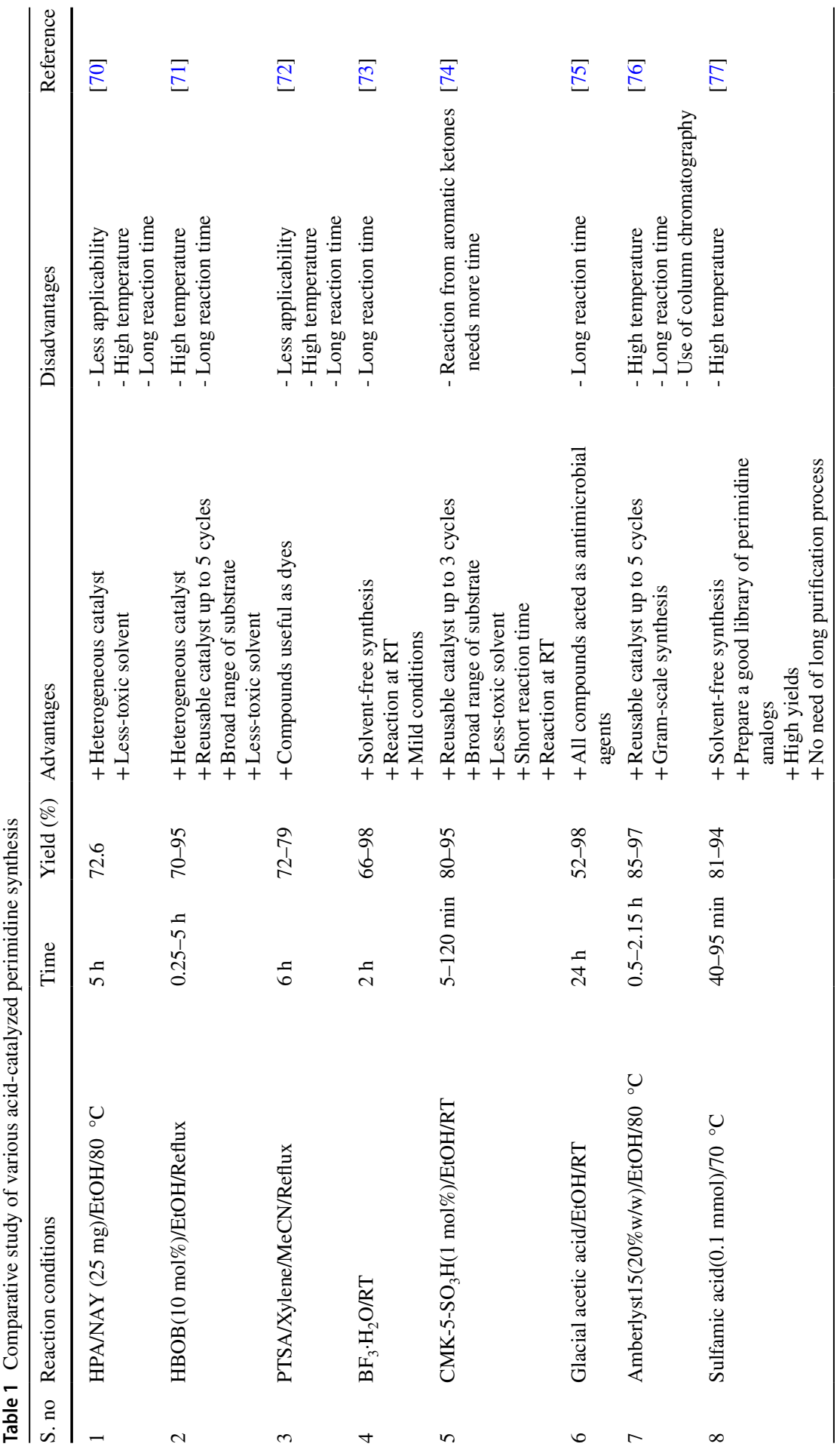




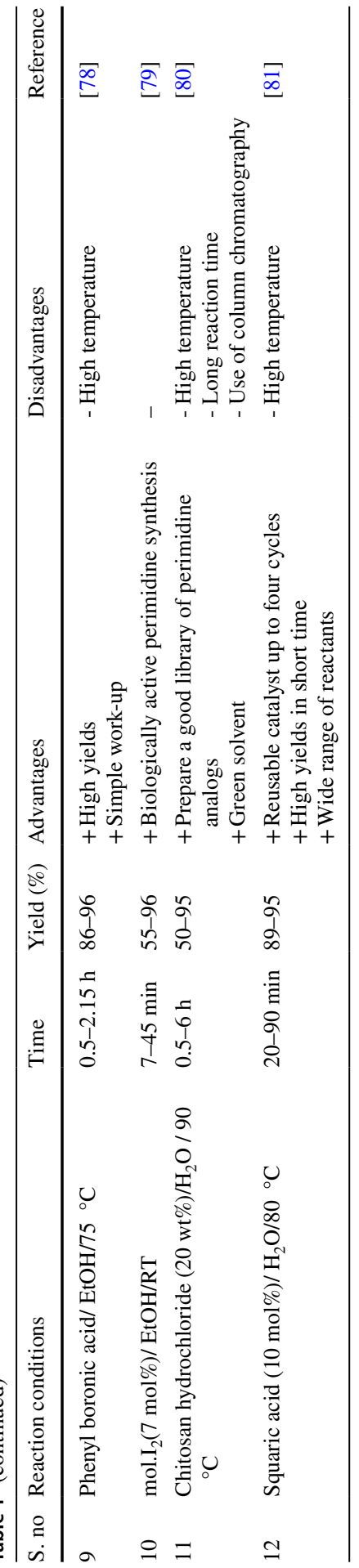




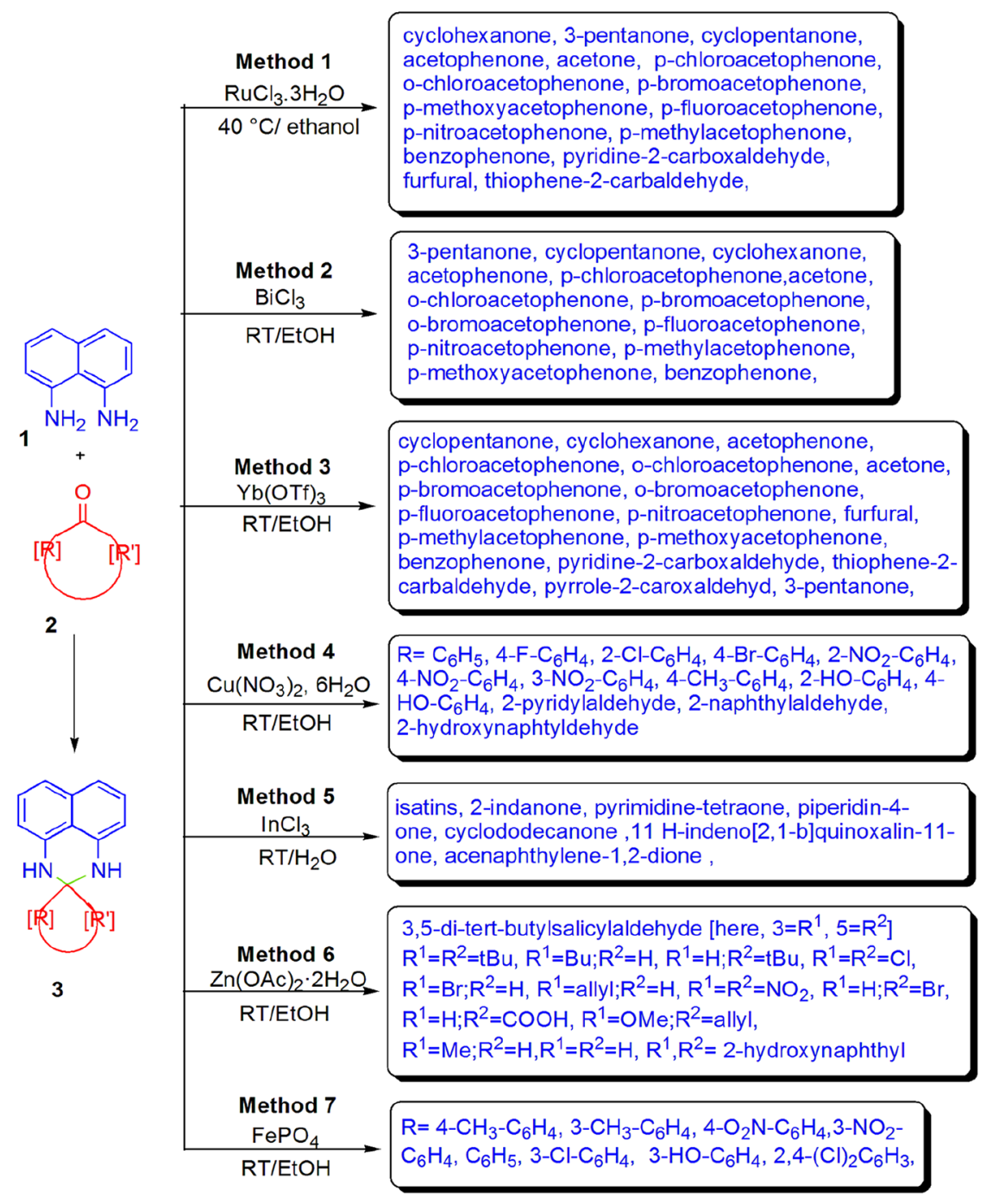

Scheme 6 Metal-catalyzed perimidine synthesis under different conditions

reaction and scope of substrate using a range of aromatic, heterocyclic, and aliphatic ketones (Scheme 6, Method 1). $\mathrm{BiCl}_{3}$ is an economic, less-toxic, and eco-benign reagent that works as a metal catalyst. A simple, reliable synthesis of perimidine derivatives from NDA and ketones in the presence of $\mathrm{BiCl}_{3}$ catalyst and ethanol at ambient temperature was reported by Zhang and companions [85]. Here, the scope of substrate was explored using aliphatic, aromatic, and alicyclic ketones. The authors also examined the effect of various bismuth salts $\left(\mathrm{Bi}\left(\mathrm{NO}_{3}\right)_{3} \cdot 5 \mathrm{H}_{2} \mathrm{O}, \mathrm{BiCl}_{3}, \mathrm{BiBr}_{3}\right)$ and other catalysts $(\mathrm{HCl})$ using different solvents 
$\left(\mathrm{CH}_{2} \mathrm{Cl}_{2}, \mathrm{C}_{2} \mathrm{H}_{5} \mathrm{OH}, \mathrm{CH}_{3} \mathrm{CN}, \mathrm{THF}, \mathrm{Et}_{2} \mathrm{O}, \mathrm{PhCH}_{3}, \mathrm{DMF}\right)$ on the yield of the reaction (Scheme 6, Method 2).

A series of substituted perimidine derivatives has been synthesized by Zhang [86] from NDA with different ketones using ytterbium(III) triflate catalyst in ethanol at room temperature in moderate to high yields. The authors also studied various influencing factors like amount of catalyst loading, use of different solvents, etc. This method has advantages like use of water stable and cheap Lewis acid catalyst, ambient conditions, wide substrate scope, easy reaction workup, and excellent yields (Scheme 6, Method 3). Mobinikhaledi and Steel [87] suggested a facile, novel, and eco-friendly route for perimidine synthesis from NDA, corresponding aldehydes, and $\mathrm{Cu}\left(\mathrm{NO}_{3}\right)_{2} \cdot 6 \mathrm{H}_{2} \mathrm{O}$ as a catalyst in EtOH at RT to afford high yields in short reaction time (Scheme 6, Method 4).

2,3-Dihydro- $1 \mathrm{H}$-perimidines were synthesized by the cyclo-condensation of NDA and different carbonyl compounds in the presence of $\mathrm{InCl}_{3}$ in water at ambient temperature by Yasaei et al. [88]. Here, $\mathrm{InCl}_{3}$ is a mild, inexpensive, easily available, non-toxic, and efficient catalyst, which produced perimidine derivatives in water as a "greener media" with high atom economy (Scheme 6, Method 5). Belmonte and co-authors [89] developed a mild, efficient, and tunable route for the synthesis of 2-aryl-substituted 2,3-dihydro- $1 H$-perimidines involving NDA with various substituted salicylaldehydes in the presence of $\mathrm{Zn}(\mathrm{OAc})_{2} \cdot 2 \mathrm{H}_{2} \mathrm{O}$ catalyst. The authors also demonstrated the synthesis of multiperimidines, which was supported by calixarenes from tetra-formyl-calix [4] arene. Easy synthesis, high yields, simple workup, applicability, and variety in substitution patterns are the notable merits of this process (Scheme 6, Method 6).

Behbahani and co-authors [90] presented a simple and efficient $\mathrm{FePO}_{4}$-promoted cyclocondensation of aromatic aldehydes and NDA with ethanol at room temperature to produce 2-substituted perimidines in good yields. Here, $\mathrm{FePO}_{4}$ worked as a versatile, low-cost, green, non-toxic, easily available, and reusable catalyst in ecobenign conditions. On optimization of the reaction conditions, the authors found that $10 \mathrm{~mol}_{\%}$ of $\mathrm{FePO}_{4}$ in ethanol at ambient temperature gave excellent results (Scheme 6, Method 7).

A $\mathrm{Cu}(\mathrm{OAc})_{2}$-catalyzed novel aerobic oxidative dehydrogenation coupling and tricyclization of NDA with 2-(phenylethynyl)-benzaldehyde to obtain heptacyclic quinolizino[3,4,5,6-kla]perimidines in moderate yields was presented by Feng et al. [91]. In this domino protocol, four new bonds and three new rings were formed via functional-group compatible approaches. The author applied different oxidants $\left(\mathrm{PhI}(\mathrm{OAc})_{2}, \mathrm{~K}_{2} \mathrm{~S}_{2} \mathrm{O}_{8}, \mathrm{Ag}_{2} \mathrm{O}, \mathrm{DDQ}\right.$, air, $\left.\mathrm{O}_{2}\right)$, base $\left(\mathrm{K}_{2} \mathrm{CO}_{3}, \mathrm{Cs}_{2} \mathrm{CO}_{3}, \mathrm{Na}_{2} \mathrm{CO}_{3}\right.$, $\mathrm{NaHCO}_{3}, \mathrm{Cs}_{2} \mathrm{CO}_{3}$ ), and solvents (DMSO, 1,4-dioxane, THF, toluene) for the feasibility of reaction. It was found that $20 \mathrm{~mol} \% \mathrm{Cu}(\mathrm{OAc})_{2}$ with base $\left(\mathrm{Cs}_{2} \mathrm{CO}_{3}\right)$, solvent (1,4-dioxane), and oxidant $\left(\mathrm{O}_{2}\right)$ at $100{ }^{\circ} \mathrm{C}$ displayed excellent outcomes (Scheme 7).

Schwob and colleagues [92] described a novel cobalt-catalyzed reductive cyclization of dinitroarene with aldehydes for the synthesis of $1 H$-perimidines with high efficiency, chemoselectivity, and high functional group tolerance. Here, dinitroarene and aliphatic and benzylic aldehydes reacted in the presence of earth copious metal catalyst cobalt and charcoal complex at $6.0 \mathrm{MPa}$ hydrogen pressure, $130{ }^{\circ} \mathrm{C}$ temperature in toluene for $20 \mathrm{~h}$ to produce $1-\mathrm{H}$-perimidines in excellent yields. The catalyst 


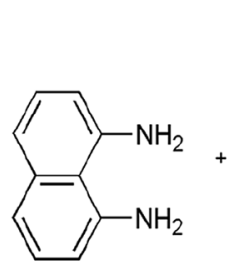<smiles>[R]c1cccc(C=O)c1C</smiles>

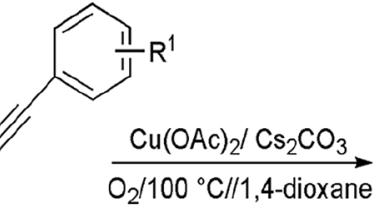

$R^{2}$

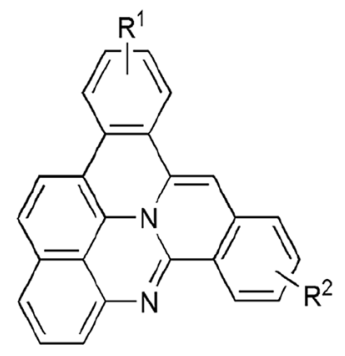

$67-81 \%$

$\mathrm{R}^{1}=\mathrm{H}$, 4-Chloro, 3-flouro, 4-methoxy, 4-ethoxy, 4-propyl

$\mathrm{R}^{2}=\mathrm{H}$, 4-Chloro, 1,3-dioxolane, 3-flouro, 3-methoxy, 3,4-dimethoxy, 4-flouro, 4-methyl, 3-chloro

Scheme 7 Perimidine synthesis from oxidative coupling and dehydrogenations

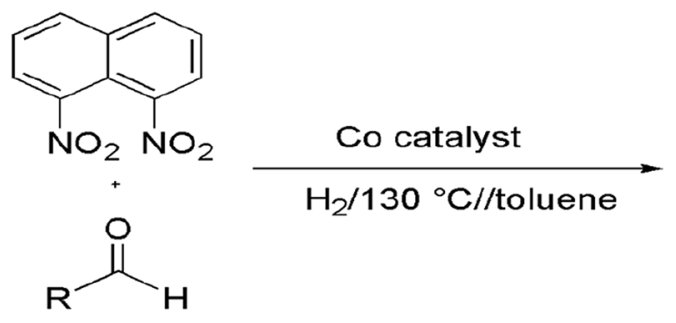<smiles>[R]C1=Nc2cccc3cccc(c23)N1</smiles>

$\mathrm{R}=\mathrm{C}_{6} \mathrm{H}_{5}, 2-\mathrm{CH}_{3}-\mathrm{C}_{6} \mathrm{H}_{4}, 3-\mathrm{CH}_{3}-\mathrm{C}_{6} \mathrm{H}_{4}, 4-\mathrm{CH}_{3}-\mathrm{C}_{6} \mathrm{H}_{4}, 4-\mathrm{F}-\mathrm{C}_{6} \mathrm{H}_{4}, 3-\mathrm{Cl}-$ $\mathrm{C}_{6} \mathrm{H}_{4}, 4-\mathrm{Cl}-\mathrm{C}_{6} \mathrm{H}_{4}, 4-\mathrm{Br}-\mathrm{C}_{6} \mathrm{H}_{4}, 4-\mathrm{I}_{6} \mathrm{C}_{6} \mathrm{H}_{4}, 4-\mathrm{CH}_{3} \mathrm{~S}-\mathrm{C}_{6} \mathrm{H}_{4}, 4-\mathrm{CH}_{3} \mathrm{O}-$ $\mathrm{C}_{6} \mathrm{H}_{4}, 4-\mathrm{HO}-\mathrm{C}_{6} \mathrm{H}_{4}, 4-\mathrm{CH}_{3} \mathrm{CO}-\mathrm{HN}-\mathrm{C}_{6} \mathrm{H}_{4}, 4-\mathrm{CN}-\mathrm{C}_{6} \mathrm{H}_{4}, \ldots$.

Scheme 8 Co-catalyzed hydrogenative synthesis of perimidines

cobalt-charcoal complex was generated via simple pyrolysis and has several merits like easy availability, facile synthesis, high catalytic activity, reusability, and stability over several cycles (Scheme 8).

Metal-catalyzed synthesis of perimidines in diverse conditions with different substituents is illustrated in Schemes 6, 7, and 8 and their comparative study is given in Table 2 .

\subsection{Nanocatalyst-Assisted Synthesis}

Nanocatalysts have a high surface-to-volume ratio and active sites that display high activity and selectivity in various heterocyclic synthesis. Nanocatalysts are easily prepared, recyclable, and show clean reaction, excellent yields in short reaction time, simple separation, and reduce the use of toxic solvents and reagents [93, 94]. 


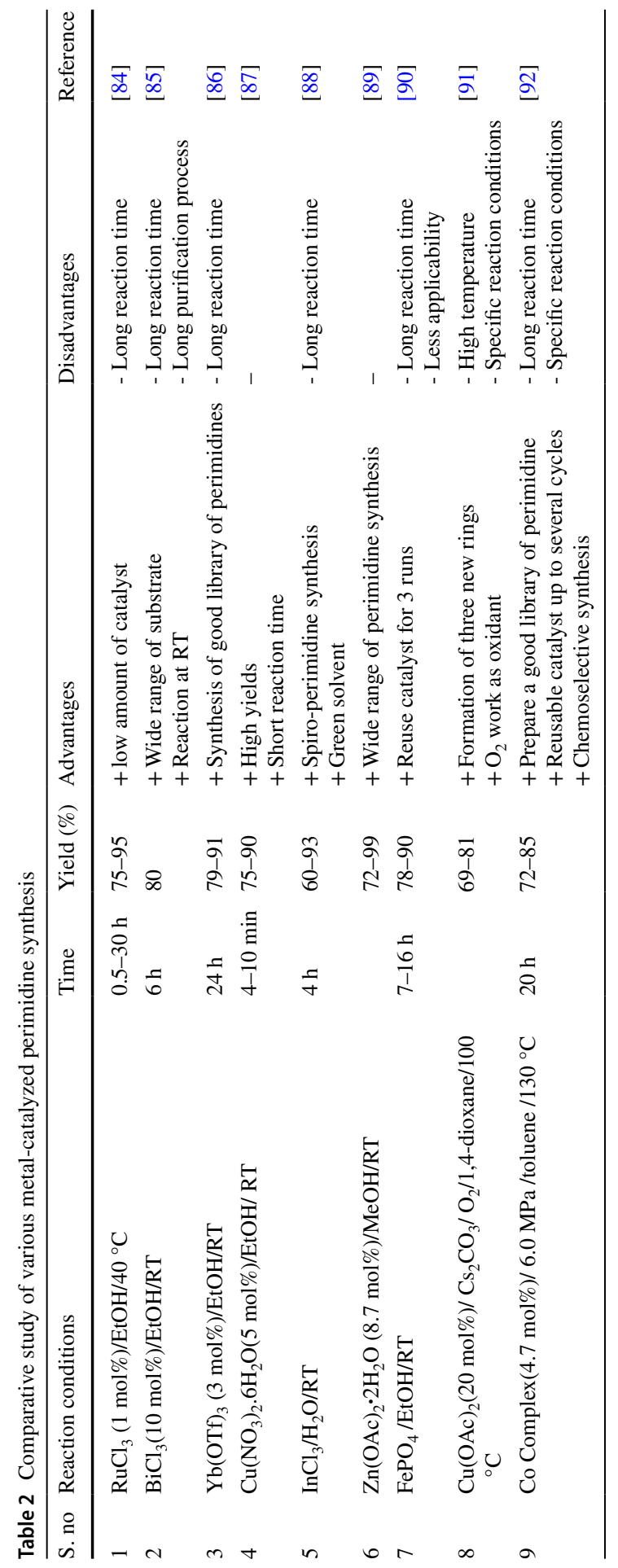


A simple, greener, and high-yielding protocol for the preparation of perimidine derivatives from condensation of NDA and aldehydes using nano-silica sulfuric acid catalyst in EtOH at RT was developed by Mobinikhaledi et al. [95]. Here, simple workup, less reaction time, and recyclability of catalyst and its reusability up to the fifth run without considerable loss in activity are attractive features of this synthesis (Scheme 9, Method 1). Kalhor et al. [96] explored the condensation of NDA with aromatic aldehydes by making use of nano-CuY zeolite system

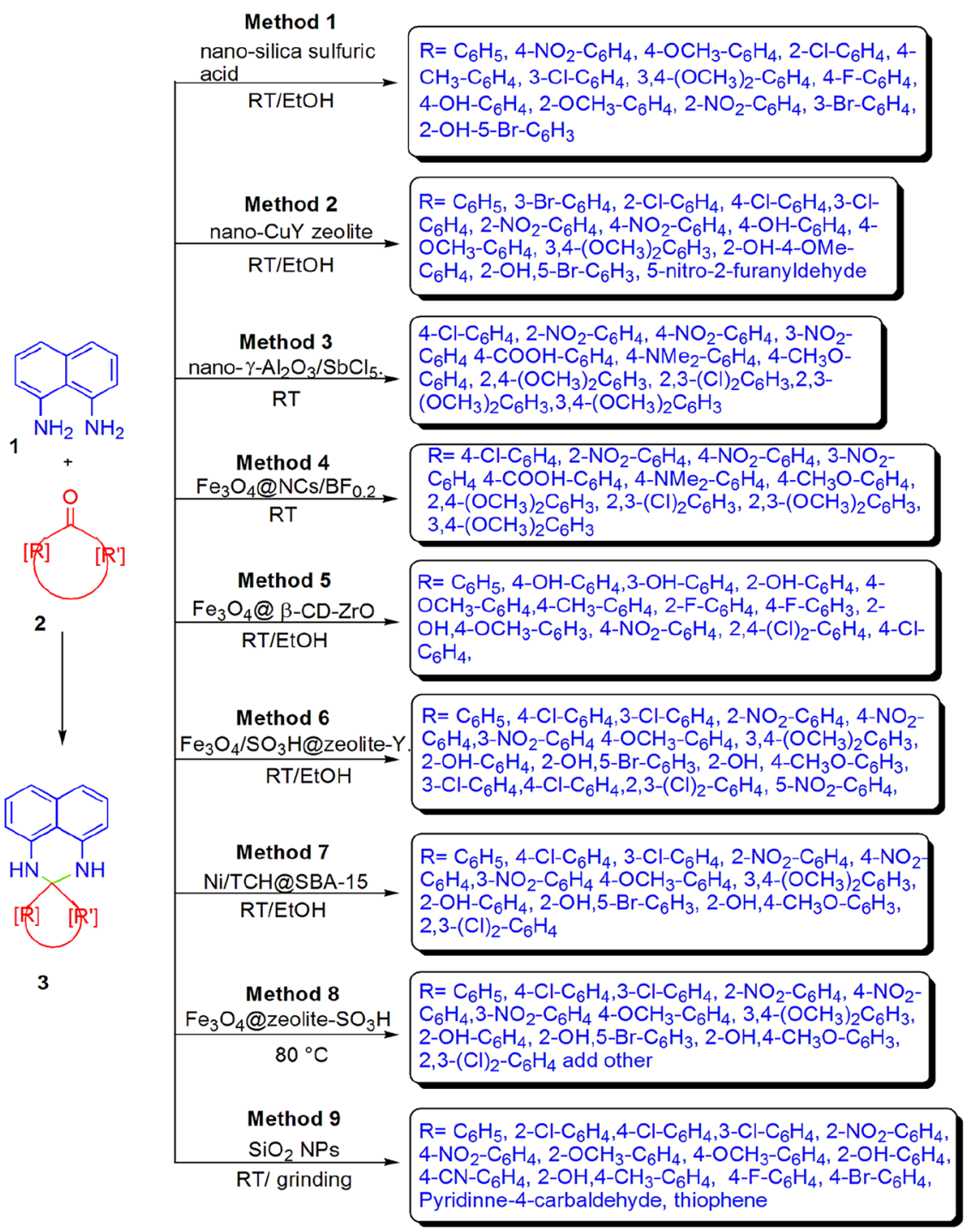

Scheme 9 Nano-particle-catalyzed perimidine synthesis in different conditions 
using ethanol at RT for the synthesis of perimidine derivatives in good yields and also examined the reusability of nano-CuY zeolite catalyst up to four cycles (Scheme 9, Method 2).

A new Lewis acid catalyst nano- $\gamma-\mathrm{Al}_{2} \mathrm{O}_{3} / \mathrm{SbCl}_{5}$ was synthesized and applied for the synthesis of perimidine derivatives by Bamonir et al. [97]. This reaction proceeded at room temperature in solvent-free conditions using NDA and substituted aromatic aldehydes via grinding to obtain high yields. For comparative study, the authors also applied different catalysts, namely zeolite, $\mathrm{Fe}_{3} \mathrm{O}_{4} / \mathrm{SiO}_{2} /$ $\left(\mathrm{CH}_{2}\right)_{3} \mathrm{~N}+\mathrm{Me}_{3} \mathrm{Br}_{3}, \mathrm{FePO}_{4}$, and nano- $\gamma-\mathrm{Al}_{2} \mathrm{O}_{3} / \mathrm{SbCl}_{5}$ in multiple amounts using ethanol and solvent-free conditions at $80{ }^{\circ} \mathrm{C}$ and room temperature. Highly efficient catalyst, simple work-up, clean reaction profile, and high yields in ambient conditions are the remarkable advantages of this method (Scheme 9, Method 3). Mirjalili et al. [98] synthesized a novel, green, nanocellulose-assisted magnetic nanocatalyst for the synthesis of 2,3-dihydro- $1 H$-perimidine from NDA and aromatic aldehydes in solvent-free conditions at ambient temperature. $\mathrm{Fe}_{3} \mathrm{O}_{4} @ \mathrm{NCs} / \mathrm{BF}_{0.2}$ possesses characteristics such as inexpensiveness, bio-based synthesis, simple separation, recyclability that makes it eco-friendly, and that it is a green nanocatalyst. The authors also applied different conditions such as room temperature, microwave irradiation, mixer mill, ultrasound using diverse solvents ( $\mathrm{EtOH}, \mathrm{MeOH}$, acetone, $\mathrm{CH}_{2} \mathrm{Cl}_{2}, \mathrm{H}_{2} \mathrm{O}$, PEG 400 and $\mathrm{H}_{2} \mathrm{O}$ : EtOH) to optimize the reaction feasibility. This protocol has some additional characteristics like easy synthesis, use of nanocatalyst, being solventfree, shorter reaction time, no need for further purification, and also excellent yield (Scheme 9, Method 4).

Amrollahi and Vahidnia [99] demonstrated the synthesis of novel catalyst $\mathrm{Fe}_{3} \mathrm{O}_{4} @ \beta-\mathrm{CD}-\mathrm{ZrO}$ and studied their catalytic efficiency for the preparation of perimidine derivatives from NDA and aromatic aldehydes. This organic-inorganic hybrid magnetic catalyst showed high potency due to its special properties like being inexpensive, heterogeneous, having a high surface area and high thermal and chemical stability, being removable from a magnet, and reusability up to four runs without any considerable loss in activity. To determine optimal conditions, the authors employed diverse catalysts $\beta$-CDCu, $\mathrm{Fe}_{3} \mathrm{O}_{4} @ \beta$-CD-Cu, $\beta-\mathrm{CD} / \mathrm{Fe}_{3} \mathrm{O}_{4}$ and $\beta$-CD$\mathrm{ZrO}$ using different amounts in various media like $\mathrm{MeCN}, \mathrm{AcOEt}, \mathrm{H}_{2} \mathrm{O}$, n-hexane, $\mathrm{EtOH}$, and $\mathrm{H}_{2} \mathrm{O} / \mathrm{EtOH}$. However, $\mathrm{Fe}_{3} \mathrm{O}_{4} @ \beta$-CD-ZrO (0.04gm) in EtOH at ambient temperature has been proven as the best conditions with respect to yields (Scheme 9, Method 5).

A new magnetic nanocatalyst $\mathrm{Fe}_{3} \mathrm{O}_{4} / \mathrm{SO}_{3} \mathrm{H} @$ zeolite-Y has been synthesized and used for the preparation of 2-aryl perimidine derivatives by Kalhor and Zarnegar [100]. In this study, the optimization of reaction was carried out using diverse amounts of catalyst in different solvents $\left(\mathrm{H}_{2} \mathrm{O}, \mathrm{EtOH}, \mathrm{MeOH}, \mathrm{CH}_{2} \mathrm{CN}\right.$, $\mathrm{CH}_{2} \mathrm{Cl}_{2}$, and $\mathrm{EtOH} / \mathrm{H}_{2} \mathrm{O}$ ) at room temperature. This method included some interesting features like eco-friendliness, simple procedure, high yields with purity, atom economy, and recyclable catalyst (Scheme 9, Method 6). Kalhor et al. [101] investigated a green nano-catalyzed synthesis of 2,3-dihydroperimidines in excellent yields from NDA and various aldehydes in EtOH with stirring at room temperature using nickel-decorated SBA-15 nanocomposite $(\mathrm{Ni} / \mathrm{TCH} @$ SBA-15). This methodology is highly convenient due to several advantages like 
clean reaction process, mild conditions, simple work-up, no need of further purification, high yield and purity in minutes, easy recoverability, and a reusable heterogeneous catalyst (Scheme 9, Method 7).

Further, an efficient $\mathrm{Fe}_{3} \mathrm{O}_{4}$ @ zeolite- $\mathrm{SO}_{3} \mathrm{H}$-catalyzed eco-friendly approach for perimidine synthesis was introduced by Kalhor and colleagues [102] from NDA and different aldehydes in solvent-free conditions at $80{ }^{\circ} \mathrm{C}$. This solid acid-based nanohybrid showed high catalytic activity with easy magnetic separation and reusability up to six times. Solvent-free conditions, less reaction time, excellent yields, purification without use of column chromatography, and ecofriendliness are the additional benefits of this protocol (Scheme 9, Method 8). Alinezhad et al. [103] demonstrated a simple, efficient, and solvent-free synthesis of 2,3-dihydro- $1 H$-perimidines from NDA and aldehydes using $\mathrm{SiO}_{2}$ nanoparticles via grind-stone technique at room temperature. In order to study optimization of reaction feasibility, the authors applied multiple solvents like $\mathrm{H}_{2} \mathrm{O}$, $\mathrm{CH}_{3} \mathrm{CN}$, EtOH, $\mathrm{CH}_{2} \mathrm{Cl}_{2}$, and THF in variation with a catalytic amount and temperature. However, the excellent conditions in reference of yields were obtained at ambient temperature in solvent-free conditions using $2 \mathrm{~mol} \%$ of catalyst. This method has mild reaction conditions, high applicability, simple work-up, good yields, and reusability up to four consecutive cycles (Scheme 9, Method 9).

Nano-particle-catalyzed synthesis of perimidines in diverse conditions with different substituents is illustrated in Scheme 9 and their comparative study is given in Table 3.

\subsection{Molecular Sieve-Catalyzed Synthesis}

The special characteristics of molecular sieves like high specific surface area, adjustable pore size, pore shape, high pore volume with good thermal, mechanical, and chemical stability, etc., increase their efficiency in catalytic processes [104].

The synthesis of perimidine derivatives in excellent yields from NDA and benzaldehyde in DMF solvent catalyzed by molecular sieve $3 \AA$ was examined by Heravi and colleagues [105]. Simple procedure, high yields, and use of cheap, easily available, and eco-benign catalyst are additional points of this synthesis (Scheme 10, Method 1). Zeolites have open structure with millions of tiny capillaries and denoted as shape-selective catalysts, which have advantages like eco-friendliness, economic efficiency, high activity, thermal stability, less by-product and waste generation, that you can combine several catalytic process, easily recoverability, and reusability. Mobinikhaledi et al. [106] explored the NaY zeolite-catalyzed arylperimidines synthesis from cyclocondensation of 1,8-diaminonaphthalene (NDA) and aldehydes in good yields. Eco-benign and mild conditions, simple work-up, and having a recyclable catalyst are attractive features of this process (Scheme 10, Method 2).

Various techniques of perimidine synthesis in diverse conditions with different substituents are illustrated in Scheme 10 and their comparative study is given in Table 4. 


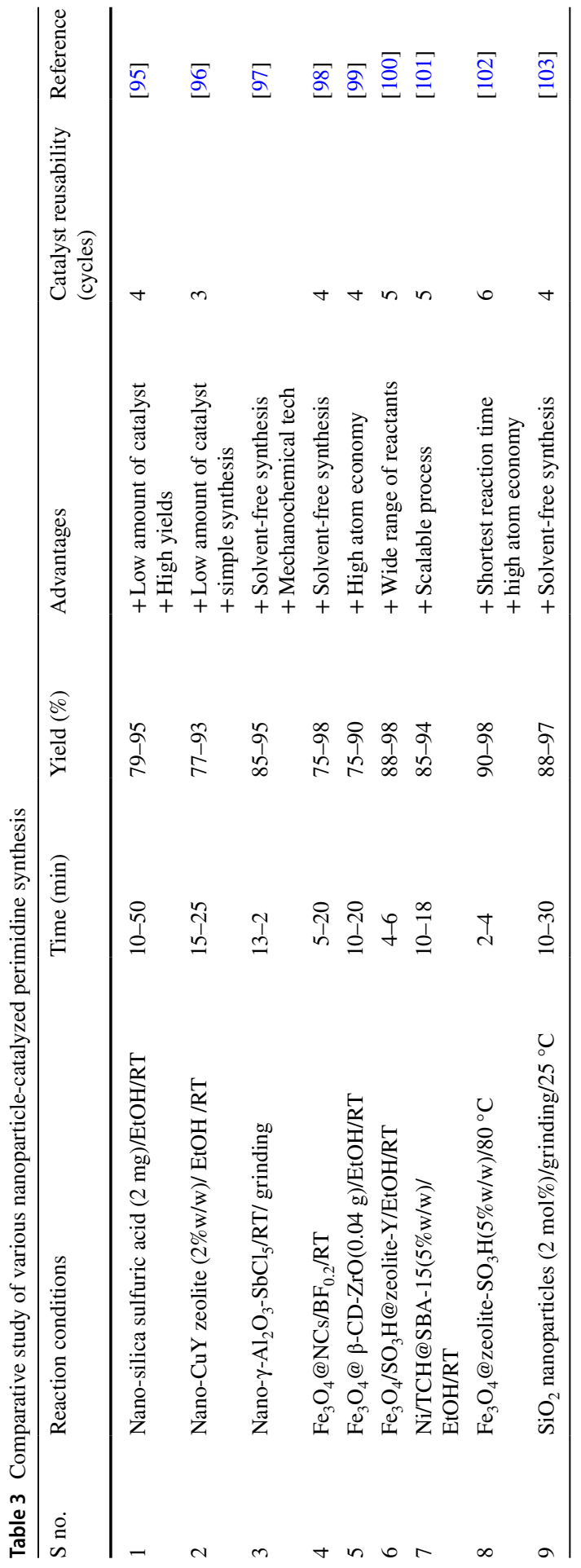




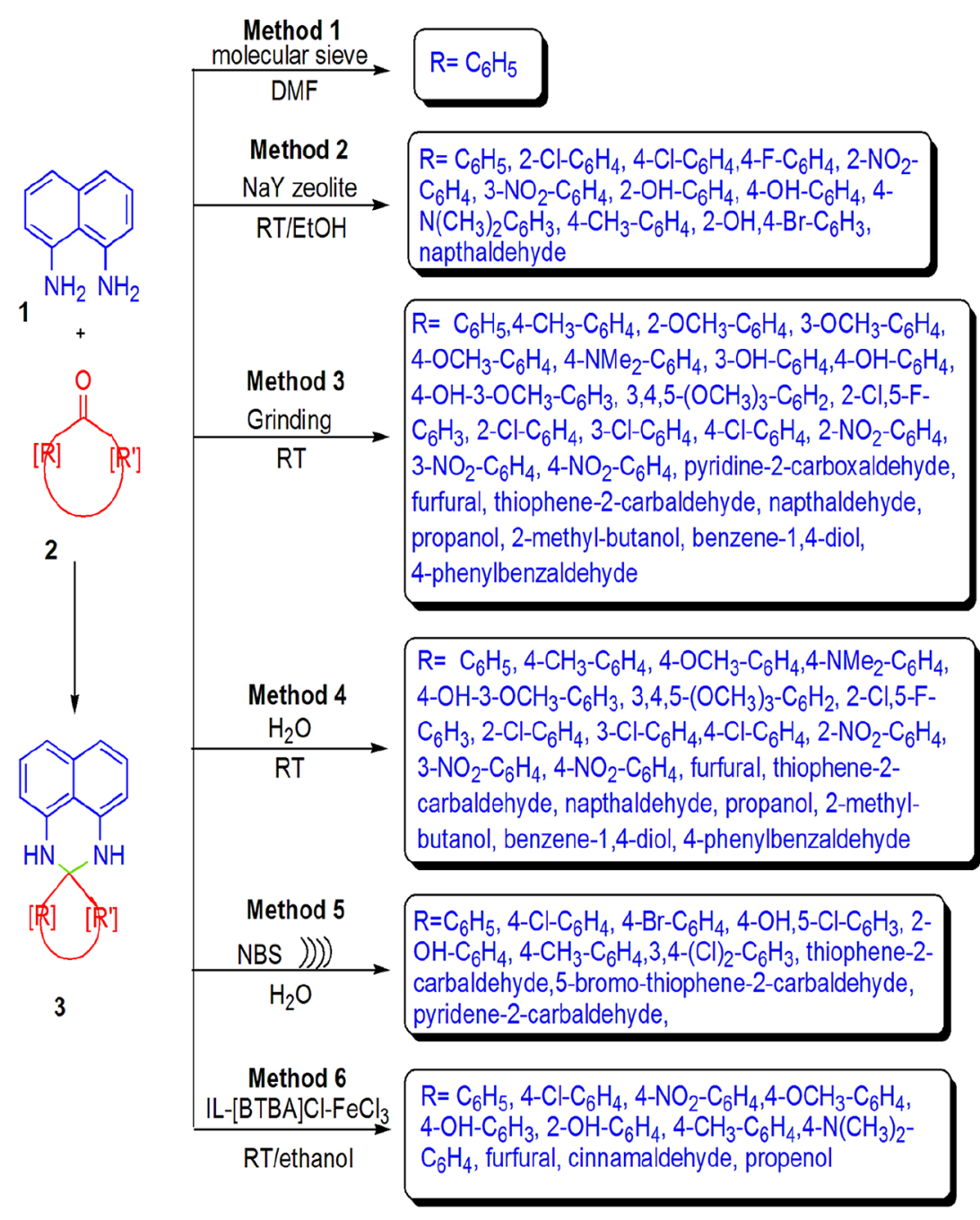

Scheme 10 Perimidine synthesis using different techniques

\subsection{Microwave-Assisted Synthesis}

Microwave-assisted synthesis follows "volumetric core heating" phenomenon where the substance absorbs the MW radiations and converts them into heat. MWI reduce reaction time and increase reaction yief Derivatives of Perimidinelds with high atom economy [107].

In 2005, Mobinikhaledi and coworkers [108] developed a new microwave-assisted (MWI) route of benzotriazole-substituted perimidine synthesis from NDA and carboxylic acid in $\mathrm{HCl}$ using the grind-stone technique. These 


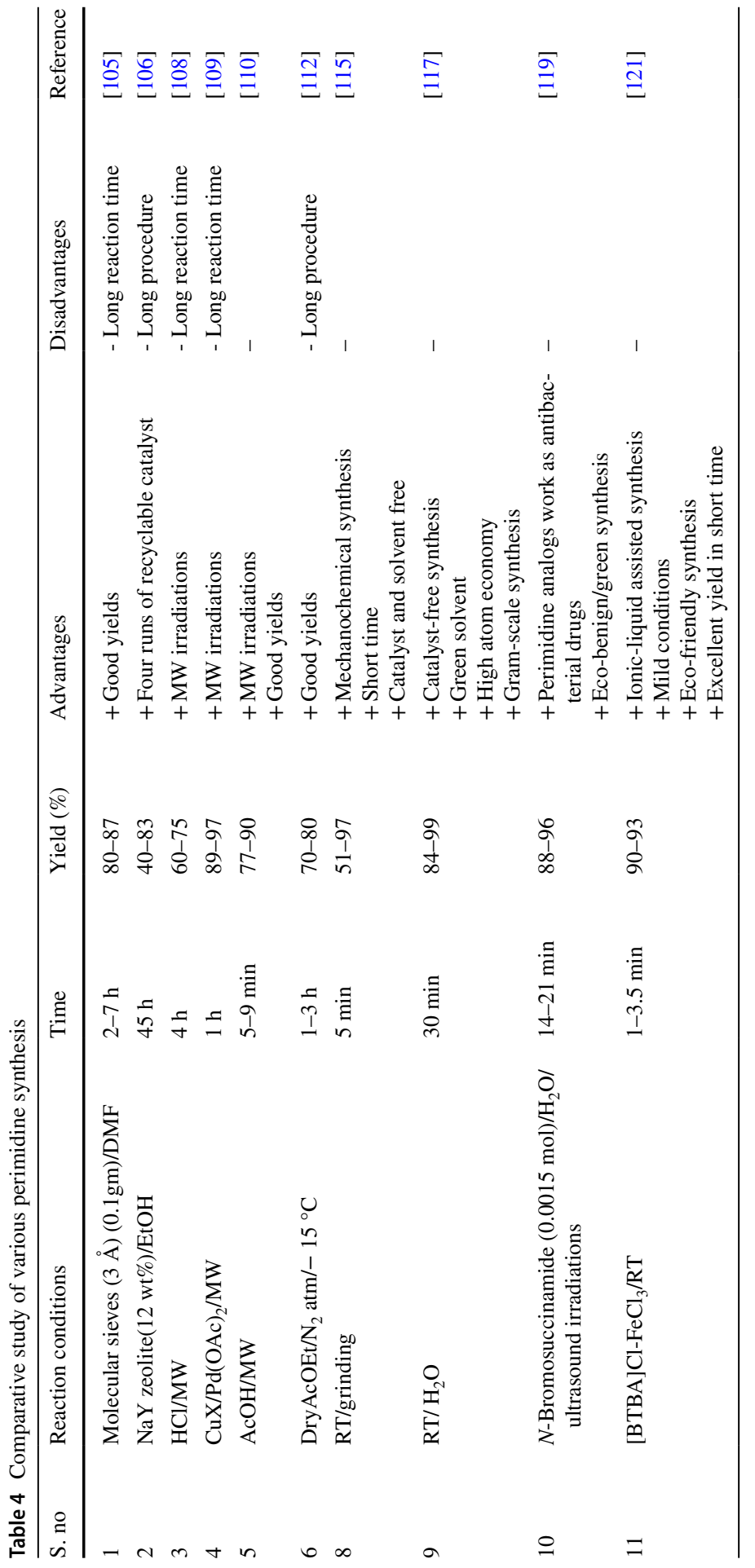




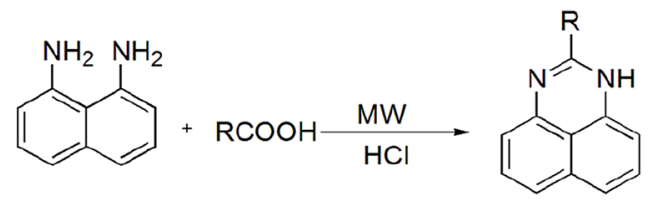

$\mathrm{R}=$ methyl, ethyl,chloromethyl, trichloromethyl, 2-(1H-perimidine-2-yl)ethyl, 4-(1H-perimidine-2-yl)butyl, (Z)-2(1H-perimidine-2-yl)-1-ethenyl

[Ref. 108]
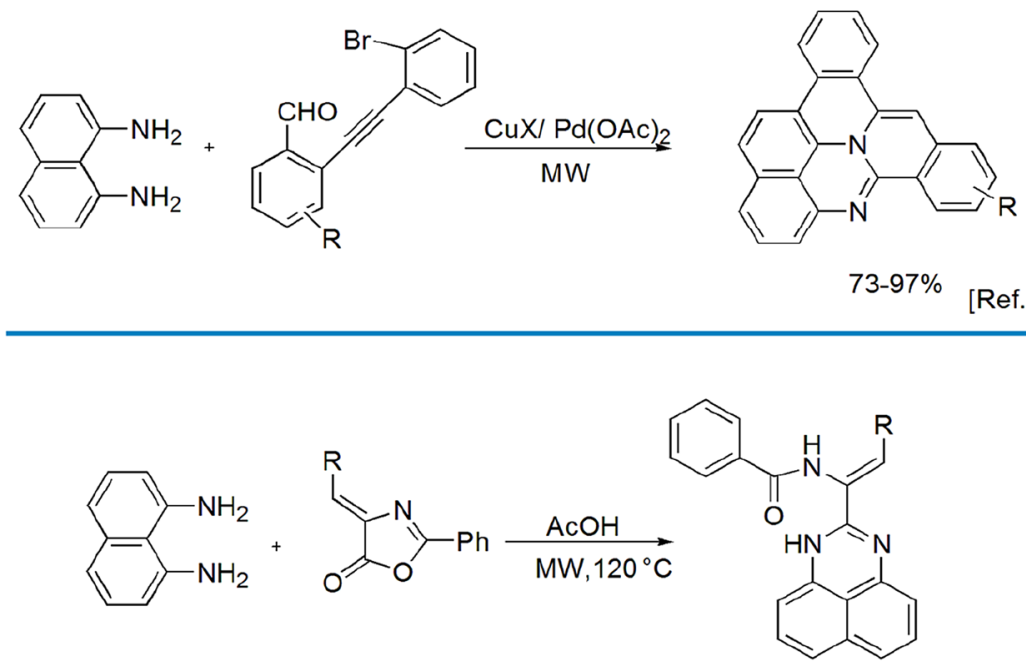

$77-90 \%$

[Ref. 110]

Scheme 11 MW-assisted perimidine synthesis in different conditions

perimidines were further refluxed with sodium amide in dry toluene to obtain benzotriazole-perimidine conjugates (Scheme 11). Tokimizu and coworkers [109] disclosed a novel, efficient, and two-step four-component synthesis of fused perimidine derivatives via palladium-catalyzed $\mathrm{C}-\mathrm{H}$ arylation in good yields. In this process, initially, copper supported annulation of NDA and 2-alkynylbenzaldehydes produced perimidines, which further underwent palladium-catalyzed $\mathrm{C}-\mathrm{H}$ arylation and gave a novel series of fused perimidines. The authors also studied the effect of varied solvents like DMF, dioxane in different conditions such as heating, reflux, MW irradiation with variation in temperature (Scheme 11).

Zhu et al. [110] reported an efficient, facile, and appropriate synthesis of (Z)$\mathrm{N}$-(2-argio-1-(1H-perimidin-2-yl)vinyl)benzamide from NDA and (Z)-4-arylmethylene-2-phenyloxazol-5(4 H)-one in glacial acetic acid (HOAc) at $120{ }^{\circ} \mathrm{C}$ under microwave irradiation in high yields. The authors also examined the effect of various solvents such as DMF, EtOH, $\mathrm{H}_{2} \mathrm{O}, \mathrm{HOAc}$, and ethylene glycol on the 
yield of reaction. Inexpensive starting material, simple procedure, and less reaction time are the merits of this protocol (Scheme 11).

\subsection{Catalyst-Free Synthesis}

Currently, organic synthesis is focused on the design of green and eco-benign processes avoiding the use of toxic catalysts and other reagents. Catalyst-based syntheses have some drawbacks such as expense, toxicity, and difficult separation and purification, which can be reduced by developing mild catalyst-free synthesis [111].

In 2003, Aly and El-Shaieb [112] demonstrated the unique reaction of NDA with some $p$-acceptors to obtain perimidine heterocycles. The reaction of NDA with tetracyanoquinodimethane (TCNQ), 2-dicyanomethyleneinNADe-1,3-dione (CNIND), and 2-(2,4,7-trinitro-9H-fluoren-9-ylidene)propane-dicarbonitrile (DTF) afforded 2-[4-(1H,3H-perimidin-2-ylidene)cyclohexa-2,5-dienylidene]malononitrile, 2-(1H,3H-perimidin-2-ylidene)-indan-1,3-dione, 2,9-spiro-[2,4,7-trinitrofluorene]-1H,3H-perimidin-2-ylidene, respectively, in moderate yields (Scheme 12). Maloshitskaya et al. [113] synthesized substituted perimidine derivatives and also studied their multicomponent chain-ring-chain tautomerism in different solutions like DMSO, $\mathrm{CF}_{3} \mathrm{COOH}$ via equilibrium constants (log $\mathrm{K}$ ), and Hammett-Brown parameters. In this method, 4-methyl and 4,4,6-trimethylhexahydropyrimidines were prepared from NDA and aromatic aldehydes at room temperature in good yields.

Akita et al. [114] introduced an innovative cyclocondensation of NDA with ninhydrin and isatin to produce perimidine derivatives. When NDA was stirred with ninhydrin in acetonitrile at ambient temperature for $24 \mathrm{~h}$, single-product spiro- $N, N$ acetal was isolated, while on refluxing and stirring NDA, isatin and $p$-toluenesulfonic acid in acetic acid for $4 \mathrm{~h}$, a mixture of perimidine derivatives were obtained in $45 \%, 9 \%$, and $6 \%$ yields. The structure of all compounds was enucleated from X-ray crystal structural study (Scheme 12).

Scheme 12 Catalyst-free perimidine synthesis in different conditions

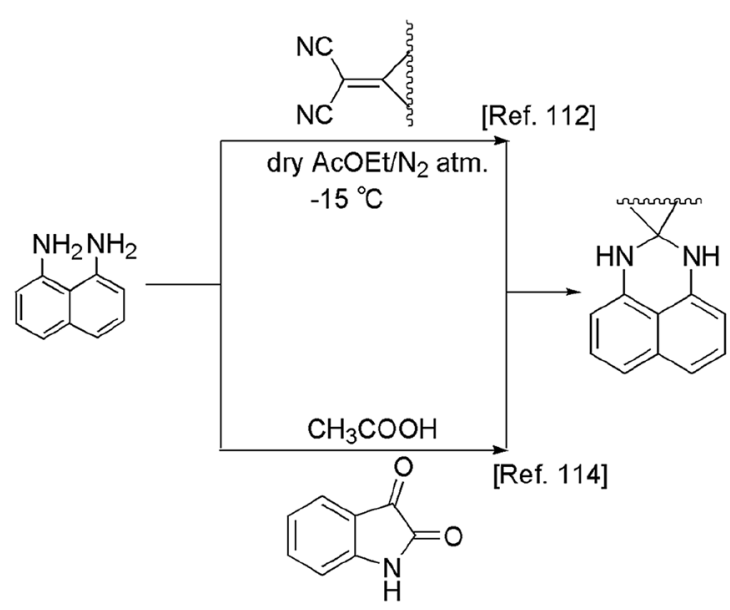


Harry et al. [115] recently developed a new and facile eco-friendly mechanochemical synthesis of perimidines from NDA and carbonyl compounds in excellent yields applying catalyst and solvent-free conditions via grinding techniques. This protocol has several advantages like synthesis of library of perimidines (25 derivatives), ambient conditions, mild protocol, simple work-up, gram-scale synthesis, high atom economy, etc. (Scheme 10, Method 3).

\subsection{On Water Synthesis}

Water is a natural green solvent in various transformations due to its high abundance, non-flammability, non-toxicity, easy handling, and purification. In this process, reactants form a heterogeneous mixture, come closer, and increase the rate of reaction. "On water" chemistry is a challenging area of organic synthesis due to the hydrophobic nature of most of the organic components but it is the fastest-growing greenest protocol for sustainable synthesis [116].

Harry et al. [117] developed a novel, eco-friendly and catalyst-free "on water" synthesis of 2,3-dihydro- $1 H$-perimidines in moderate to high yields from NDA and various aromatic, aliphatic, and heterocyclic aldehydes at room temperature in $30 \mathrm{~min}$. The authors also studied the effect of various conditions like catalyst $\left(\mathrm{NiCl}_{2} \cdot 6 \mathrm{H}_{2} \mathrm{O}\right.$, without catalyst), solvents $\left(t-\mathrm{BuOH}\right.$, EtOH, and $\left.\mathrm{H}_{2} \mathrm{O}\right)$ and temperature $\left(80{ }^{\circ} \mathrm{C}{ }^{\circ} \mathrm{C}, \mathrm{RT}\right)$ on the reaction and found that, without a catalyst, "on water" synthesis at ambient temperature gave the best results. The yield of the reaction was not much affected by the substitution of aldehydes but was altered from steric hindrance. However, ketones did not produce corresponding products from this protocol (Scheme 10, Method 4).

\subsection{Ultrasound-Assisted Synthesis}

In organic synthesis, ultrasound irradiation works via cavitation phenomenon. In a reaction mixture, a large number of cavitation bubbles produce that work as microreactors and breaking of cavitation generates high temperature and pressure that can display new bonding in reactants and form new compounds. Ultrasound-assisted synthesis is a powerful and eco-friendly technique in various areas of synthetic chemistry due to its significant properties, viz., simple operation, avoidance of the use of toxic solvents and catalysts, clean reaction profile, high efficiency in terms of reaction time, product selectivity, yields, waste reduction, and energy conservation [118].

Krishna and Thriveni [119] reported a proficient and improved catalyst, $N$-bromosuccinamide (NBS), for the condensation of NDA and aromatic aldehydes using green solvent and water to form corresponding perimidines in good yields under both ultrasound irradiation and conventional heating. From a comparative study in both synthetic methods, the authors evaluated that under ultrasonication, reaction proceeded more conveniently as compared to traditional methods in terms of reaction time, yields, and by-product generation. Further, all compounds were screened for antimicrobial activity against bacterial strain $S$. aureus, E. coli, P. aeruginosa, 
and fungal strain C. albicans, A. flavus, A. fumigatus against reference drugs ampicillin and flucanazole, respectively. Among all the synthesized derivatives, bromoand chloro-substituted perimidines showed better activity against standard drug as compared to other compounds (Scheme 10, Method 5).

\subsection{Ionic Liquid-Assisted Synthesis}

Ionic liquids, commonly used as green solvents, consist of organic cations like pyridinium, phosphonium, and ammonium and organic and inorganic anions, viz., alkylsulfonate, trifluoroacetate, halides etc. They have special characteristics such as present in liquid state at room temperature, non-flammable, low vapor pressure, low toxicity, high thermal and chemical stability, high heat capacity, high conductivity, and recyclability, which make them applicable in green synthesis [120].

A simple, reliable, and efficient ionic liquid [BTBA]Cl- $\mathrm{FeCl}_{3}$-assisted perimidine synthesis from the reaction of NDA and aldehydes at ambient conditions in excellent yields was investigated by Bahrami and Saleh [121]. High functional group tolerance, solvent-free, low cost, shortest reaction time (1-3.5 min) and mild reaction conditions are the attractive features of this synthesis (Scheme 10, Method 6).

\section{Applications in Various Fields}

\subsection{Biologic Applications}

In 1966, Wasulko and coworkers [122] designed and developed a series of dihydroperimidines and screened them as antineoplastic agents. NDA and carbonyl compounds were refluxed in ethanol for $1-2 \mathrm{~h}$ to obtain respective dihydroperimidines. All the compounds were evaluated for antineoplastic properties against L1210 lymphoid leukemia, Sarcoma 180, and Lewis lung carcinoma. Some of the synthesized compounds worked as potent antineoplastic agents, viz., compound $4 \mathbf{a}$ against Sarcoma180 and Lewis lung carcinoma, $\mathbf{4 b}$ against Sarcoma 180, and $\mathbf{4 c}$ against Lewis lung carcinoma and tissue culture (KB) (Scheme 13).

In 1987, Herbert and coworkers [123] synthesized a range of diverse perimidines 5 and studied their DNA-binding and cytotoxic properties and anti-tumor activity. According to physiochemical properties, they revealed that fused tricyclic perimidines was the minimal structure condition for the intercalative binding with DNA and affected by the variation in side chain of chromophore. These compounds showed $\log K$ (DNA association constants) value 5.8-6.5, ICm (cytotoxic potency) $500-1500 \mathrm{nM}$ as compared to linear anti-tumor compounds.

Brafial et al. [124] described the synthesis, cytotoxic activity, and structure-activity relationship (SAR) of 2-substituted perimidines. Perimidines were synthesized from the reaction of NDA with different compounds like $p$-toluenesulphonate and cyanamide and substituted amines. The pharmacological study demonstrated that compound 6 showed cytotoxicity due to the presence of basic nitrogen bearing two methyl groups (Scheme 13). In 1999, Luthin and co-authors [125] developed a 
<smiles>[R]N1c2cccc3cccc(c23)N([R])C1(CCC)CCC</smiles>

$a, \mathrm{R}=\mathrm{H}, \mathrm{n}=3$; b, $\mathrm{R}=\mathrm{H}, \mathrm{n}=2$; c, $\mathrm{R}=\mathrm{CH} 3, \mathrm{n}=3$<smiles>[R]C1=Nc2cccc3cccc(c23)N1[R]</smiles>

5<smiles>CN(C)CC1=Nc2cccc3cccc(c23)N1</smiles>

6<smiles>NC1CCCCC1NCC(=O)C1=c2c(=O)nc[nH]c2=C2c3[nH]c(NC4CCCCC4)c(c32)-c2ccccc21</smiles>

$\mathrm{R}=\mathrm{H}, \mathrm{NHR}$, SR', $\mathrm{CH}_{2}$ CONHR', CONHR' $\mathrm{R} "=\mathrm{H}, \mathrm{R}$<smiles>[R2]Nc1ccc2nc(N[PH])nc3c2c1C(=O)c1c([Y])ccc([Y])c1-3</smiles><smiles>Cc1ccc(-n2nc(C(=O)Oc3ccccc3)c(C3=Nc4cccc5cccc(c45)N3)c2C)cc1</smiles>

10

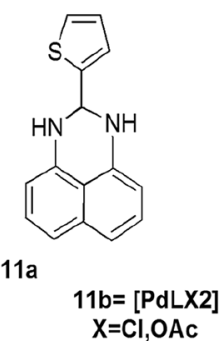

$\mathrm{X}=\mathrm{Cl}, \mathrm{OAC}$<smiles>[Y]c1ccc2c(c1)NC1(Nc3cccc4cccc(c34)N1)C(=O)N2</smiles>

9

$\mathrm{Y}=5-\mathrm{CH}_{3}, 5-\mathrm{Cl}, 5,7-\mathrm{di} \mathrm{CH}_{3}$

12<smiles>O=C(C1=c2[nH]c3cccc4cccc(c43)n2C(=O)/C1=N\Nc1ccccc1)c1ccccc1O</smiles>

Scheme 13 Some synthesized biologically active perimidine scaffold

library of oxo-7H-benzo[E]perimidine-4-carboxylic acid derivatives and evaluated them as first non-peptide antagonist for corticotropin release factor $\mathrm{CRF}_{1}$ and $\mathrm{CRF}_{2 \beta}$ receptors. $\mathrm{CRF}_{1}$ and $\mathrm{CRF}_{2 \beta}$ are the physiological mediators of the stress response and are produced from pituitary glands. Among all the synthesized compounds, compound 7 revealed the most promising action to antagonize CRF through in vivo studies (Scheme 13).

A range of cytotoxic benzoperimidine compounds $\mathbf{8}$ was developed and their activity against multidrug resistance was described by Dzieduszycka and coworkers [126] (Scheme 13). For perimidine synthesis, the authors used substituted 9,10-anthracenedione and their analogs as starting materials. The authors studied membrane affinity of the synthesized compounds for the validation of their cytotoxic characteristics and in vitro activity against different leukemia cell lines. All compounds showed high resistance indexes against tumor cells. P-gp-dependent efflux pumps (MDR) and structural features played a significant role in cytotoxicity.

Arya and Dandia [127] developed an efficient route for the regioselective synthesis of spiro perimidines using isatin and NDA with morillonite KSF under MWI in 
excellent yields in 5-7 min and evaluated antitumor activity against human malignant cell lines: cervical (HeLa), breast (MCF-7), colon (CaCo-2), laryngeal carcinoma (Hep-2), and normal human fibroblast cell lines (WI-38). All the tested molecules displayed good antitumor activity (IC50 value $9 \times 10-5$ to $5 \times 10-4 \mathrm{~mm}$ ) and compound 9 was found highly potent (Scheme 13).

A wide range of substituted and fused perimidines was prepared from hydrozonoyl chloride and ketene aminals by Farghaly and co-authors [128] and their antitumor activity was studied against liver (HEPG-2) and breast (MCF-7) cancer cell lines. Furthermore, 8,10-disubstituted-[1,2,4]triazolo[4,3- a]perimidines were also synthesized from perimidine-2-thione. All of the studied compounds showed promising antitumor activity, while compound 10 (Scheme 13) exhibited high potency with IC50 value 0.59 (HEPG-2), 0.49(MCF-7) against both cancer cell lines as compared to the reference drug doxorubicin. The SAR study revealed that pyrazolyl and triazole ring fused with perimidine ring seemed more active for tumor treatment as compared to pyrrole ring-fused perimidine ring. Azam et al. [129] developed two $\mathrm{Pd}$ (II) complexes of 2-(2-thienyl)2,3-dihydro- $1 H$-perimidine ligand from the reaction of NDA and 2-thiophenecarboxaldehyde and screened them for antimicrobial activity against six bacterial strains E. coli, S. aureus, P. aeruginosa, Citrobacter sp., Bacillus subtilis, and S. acidaminiphila. Both complexes 11a[L] and 11b [PdLX2] (Scheme 13) were found highly potent as compared to their respective ligands and also displayed good DNA binding affinity with calf thymus DNA.

Furthermore, Farghaly and coworkers [130] developed a novel series of pyrrolo[1,2- $a$ ]perimidines and evaluated their activity against three tumor cell lines, UACC-62, MCF-7, and TK-10 and their antioxidant behavior too. These bioactive compounds were prepared from the reaction of NDA with 4-hydroxycoumarin and hydrazonoyl chlorides in $\mathrm{Et}_{3} \mathrm{~N}$ and dioxane in good to high yields. Among all the synthesized compounds, compound 12c (Scheme 13) exhibited high growth inhibition activity against MCF-7 and TK-10 cell lines with TGI values $21.87,25.28 \mu \mathrm{M}$ / $\mathrm{ml}$, respectively. Some of the derivatives were found less effective against tumor cell lines and showed low to moderate results for antioxidant study as compared to Trolox.

A novel range of perimidine analogs were synthesized from the reaction of NDA and substituted iminoester hydrochloride in moderate yields via microwave irradiations by Mentee et al. [131] The synthesized compounds were screened for lipase inhibition activity against orlistat, an anti-obesity drug. Compound $\mathbf{1 3}$ behaved as a good antilipase agent with 98.6 and $63.9 \%$ inhibition at $9.375 \mu \mathrm{g} / \mathrm{ml}$ concentration (Scheme 14). Alam et al. [132] synthesized 2-(thiophen-2-yl)-2,3-dihydro-1H-perimidines (11a) by the reaction of 2-NDA and thiophenecarboxaldehyde in methanol under reflux conditions. The synthesized compounds showed profound activity against acetylcholinesterase (AChe) and exhibited AChe inhibition property with $\mathrm{IC}_{50}$ value of $0.34 \mu \mathrm{M}$. The reason behind promising activity might be the lowering of HOMO-LUMO energy gap and extra non-bonding interaction to the amino acids (Scheme 14).

Zhang et al. [133] synthesized novel triazole-containing perimidine derivatives and studied their efficiency as anti-inflammatory agents in an LPS-stimulated inflammation model with the MTT assay. These bioactive compounds were prepared 


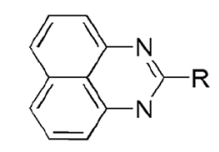

$\mathrm{R}=2,4-\mathrm{Cl}_{2} \mathrm{C}_{6} \mathrm{H}_{3} \mathrm{CH}_{2}$ $\mathrm{R}=3-\mathrm{BrC}_{6} \mathrm{H}_{4} \mathrm{CH}_{2}-$

13

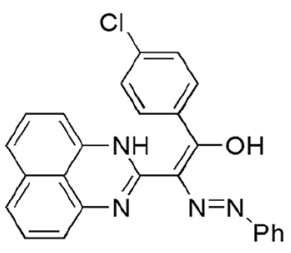

16

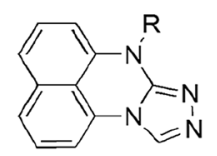

$\mathrm{R} ; \mathrm{a}=3-\mathrm{CH}_{3} \mathrm{C}_{6} \mathrm{H}_{4} \mathrm{CH}_{2}-$ $\mathrm{b}=4-\mathrm{FC}_{6} \mathrm{H}_{4} \mathrm{CH}_{2}-$

14<smiles>Cc1ccc(-n2nc(C(=O)Nc3ccccc3)c(C3=Nc4cccc5cccc(c45)N3)c2C)cc1</smiles>

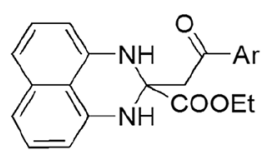

$\mathrm{a}=4-\mathrm{CH}_{3} \mathrm{C}_{6} \mathrm{H}_{4}$ $\mathrm{b}=4-\mathrm{BrC}_{6} \mathrm{H}_{4}$

$15 a, b$<smiles>[R]C1=NN([Al])C2=Nc3cccc4cccc(c34)N12</smiles>

18a, $\mathrm{R}=\mathrm{COCH}_{3}, \mathrm{Ar}=4-\mathrm{FC}_{6} \mathrm{H}_{4}$;

b, $\mathrm{R}=\mathrm{COOC}_{2} \mathrm{H}_{5}, \mathrm{Ar}=4-\mathrm{NO}_{2} \mathrm{C}_{6} \mathrm{H}_{4}$<smiles>[R]C(=O)c1nn([Al])cc1C(=O)C1=NN(c2ccccc2)C2=Nc3cccc4cccc(c34)N12</smiles>

19 and 20

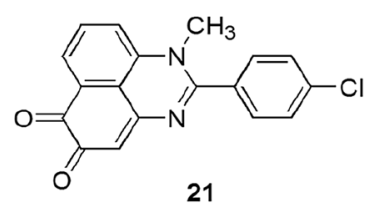

$\mathrm{R}$ for $19=\mathrm{OEt}, \mathbf{2 0}=\mathrm{NHPh}$

Ar: $\mathbf{a}=\mathrm{Ph} ; \mathbf{b}=4-\mathrm{MeC}_{6} \mathrm{H}_{4} ; \mathbf{c}=4-\mathrm{ClC}_{6} \mathrm{H}_{4} ; \mathbf{d}=4-\mathrm{NO}_{2} \mathrm{C}_{6} \mathrm{H}_{4}$

Scheme 14 Some synthesized biologically active perimidine scaffolds

from starting material NDA, carbamide and hydrazine hydrate and further refluxed them with formic acid and alkyl halide. Among all the synthesized compounds, compounds 14a and 14b reduced the level of interleukin (IL)-6 in RAW264.7 cells and pro-inflammatory cytokines - tumor necrosis factor (TNF)- $\alpha$. The in vivo study results revealed the high potency of compounds $\mathbf{1 4 a}$ and $\mathbf{1 4 b}$ with 42.94 and $49.26 \%$ inhibition, respectively, at $50 \mathrm{mg} / \mathrm{kg}$ dose as compared to ibuprofen. Western blotting outcomes also demonstrated the efficiency of $\mathbf{1 4 b}$ via inhibition of both MAPK (mitogen-activated protein kinase and p38) phosphorylation and NF- $\mathrm{BB}$ (LPSinduced nuclear factor- $\kappa \mathrm{B}$ ) activation. These results were also confirmed by the docking study with COX-2 binding site as compound 14b also showed COX-2 activity inhibition (Scheme 14).

Abu-Melha and coworkers [134] synthesized perimidine derivatives and discussed their mechanism, tautomeric forms, and pharmacological applications. The reaction of NDA took place with ethyl aroylpyrovate in ethanol up to $5 \mathrm{~h}$ to obtain $75-68 \%$ yields of substituted perimidines. Authors also demonstrated the mechanism and different tautomeric forms of derivatives from computational 
study. These derivatives were screened for two fungi (A. niger and G. candidum), four Gram-positive bacteria ( $S$. aureus, S. epidermidis, B. subtilis, S. pyogenes) and four Gram-negative bacteria (P. aeruginosa, E. coli, K. pneumoniae, S. typhimurium) against reference drugs, amphotericin B, ampicillin, and gentamicin, respectively. Among all the tested compounds, 15a, 15b, and 16 revealed high antimicrobial activity against standard drugs (Scheme 14). Kumar et al. [135] designed tetracyclic and pentacyclic perimidines from NDA and dicarbonyl compounds using microwave techniques and further evaluated their ability to suppress the growth of cancer cell lines. The in vitro antiproliferative activity was studied against five human cancer cell lines (breast T47D, lung NCl H-522, liver HepG2, colon HCT-15, ovary PA-1) using the MTT assay at $10 \mu \mathrm{M}$ concentration. All the synthesized compounds displayed low anticancer activity against reference drugs.

Eldeab and colleagues [136] synthesized a variety of perimidine conjugates and evaluated their cytotoxicity against liver carcinoma (HepG2) and human breast (MCF-7) cancer cell lines. 2-(1H-perimidin-2- $(3 H)$-ylidene) derivatives were synthesized by the reaction of naphthalene-1,8-diamine and $\beta$-keto esters with potassium carbonate under microwave irradiation (MWI). They were further reacted with suitable hydrazonoyl chloride to form 4-( $1 H$-perimidin-2-yl)$1 H$-pyrazole-3-carboxamides and pyrrolo[1,2-a]-perimidin-10-ones using a catalytic amount of piperidine under microwave irradiation. When perimidine thione was used, perimidine conjugate, $8 H$ - $[1,2,4]$ triazolo[4,3-a]perimidine was obtained. All the synthesized compounds showed good anticancer activity with $\mathrm{IC}_{50}$ value of 0.59 to $>50 \mu \mathrm{g} / \mathrm{ml}$ (HepG2) and 0.49 to $>50 \mu \mathrm{g} / \mathrm{ml}$ (MCF). Compounds 17c, 18a, and 18g exhibited maximum cytotoxic action against both tested cell lines in comparison with the reference drug doxorubicin (Scheme 14).

Masaret and Farghaly [137] synthesized a series of 8,10-disubstituted-triazoloperimidines by the reaction of different enaminones with substituted perimidines and explored their antimicrobial activity against two types of fungi (A. fumigates, C. albicans), Gram-positive (S. pneumoniae, B. subtilis) and Gram-negative ( $P$. aeruginosa, E. coli.) bacteria using agar diffusion method. Among all the synthesized compounds, compound 19c was found to be the most potent against fungi, A. fumigates (90\%) and C. albicans (82\%). Compounds 19a, 19d, and 20b were found most active against $S$. pneumoniae and others showed mild activity against ampicillin. Compounds 19c and 20a showed high potency against $P$. aeruginosa and $E$. coli (Scheme 14). A library of novel perimidine $o$-quinone conjugates was developed and examined for cytotoxicity against the four human cancer cell lines HL-60, Huh7, Hct116, and Hela by Zhou et al. [138]. All of the compounds showed profound anti-proliferative activity and SARs study explained that the position of $o$-quinone in ring A or ring B and presence of EWG (electron-withdrawing group) at the $\mathrm{C}-2$ position played an important role in controlling the cytotoxicity of the cell lines. Among the synthesized compounds, compound 21 showed the highest toxicity against HL-60/MX2 $(0.47 \mu \mathrm{M})$ and Huh7 cell lines and good Topo II $\alpha$ catalytic inhibitory activity $\left(\mathrm{IC}_{50}=7.54 \mu \mathrm{M}\right)$. These results were also confirmed from cell apoptosis assay and cell-cycle assay that made them an important target for cancer chemotherapy (Scheme 14). 


\subsection{Synthesis of Derivatives of Perimidine}

In 1994, Molina and coworkers [139] prepared substituted quinazolino[3,4-a]perimidine derivatives 22 from substituted perimidines and iminophosphoranes with isocyanate, $\mathrm{CO}_{2}, \mathrm{CS}_{2}$, and $\mathrm{CH}_{3} \mathrm{COCl}$ via aza-Witting reaction [Scheme 15].

Panchasara and Pande [140] synthesized 3-chloro-1-(4-perimidine methylcarbonylamino)-4-phenyl-azetidin-2-ones from perimidine-1-acetic acid hydrazide with corresponding carbonyl compounds and azomethine. They showed antimicrobial properties against Gram-positive (S. aureus and B. subtilis) and Gram-negative ( $S$. typhi, K. promioe, and E. coli) bacteria and plant pathogenic microbes (Nigrospora sp., B. thiobromine, aspergillus, albicans, and $F$. oxysporium). Derivatives 23a-c showed high antibacterial properties against reference drug tetracycline (Scheme 15).

A simple and efficient method for the synthesis of isoindolo[2,1-a]perimidin12-one $\mathbf{2 4}$ was developed by the reaction of heterocyclic ketene aminals (HKA) (cyclic 1,1-enediamines) and dialkylacetylenedicarboxylates (DAAD) in the presence of EtOAc and DMAP in reflux conditions by Ungoren and coworkers [141]. In this approach, benzene and pyrrole rings were simultaneously formed with isoindole nucleus in a single operation that made them promising in organic synthesis (Scheme 15).

Chen et al. [142] synthesized four $p$ - and $o$-nitro substituted 2-methyl-2-phenyl-2,3-dihydro- $1 H$-perimidine derivatives by the reaction of nitro-substituted acetophenones and NDA and explored their photochemical properties. Among the synthesized derivatives, compound 25a was found sensitive to visible light. When it was exposed to visible light in either argon atmosphere or aerobic conditions, it got converted to $2 \mathrm{H}$-indazole $\mathbf{2 6 \mathbf { a }}$ and perimidinone $\mathbf{2 6 \mathbf { b }}$ by pyrimidine oxidation and pyrimidine ring-opening/deoxygenation, respectively (Scheme 16).

$\mathrm{Wu}$ et al. [143] investigated a potent pathway for the synthesis of perimidinones 27 in moderate to good yields via aerobic oxidation of 2,3-dihydro- $1 \mathrm{H}$-perimidines using $\mathrm{Ru}(\mathrm{bpy})_{3}{ }^{2+}$, a visible light photoredox catalyst and acetonitrile as a solvent. This photo-oxidation was sensitive to substituents on amine groups

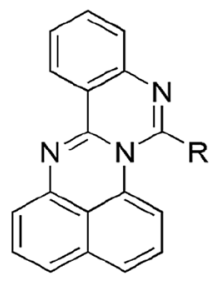

22<smiles>[R]C1C(Cl)C(=O)N1NC(=O)CN1C(C)=Nc2cccc3cccc1c23</smiles>

23 $\mathrm{a}=4-\mathrm{OCH}_{3}-\mathrm{C}_{6} \mathrm{H}_{4} ; \mathrm{b}=4-\mathrm{Cl}-\mathrm{C}_{6} \mathrm{H}_{4}$; $\mathrm{c}=2-\mathrm{NO}_{2}-\mathrm{C}_{6} \mathrm{H}_{4}$<smiles>[R]OC(=O)c1c(C(=O)O[R])c2c([R])c3c4nc5cccc(cccc-4n-3c2=O)c5c1C(=O)O[R]</smiles>

24

Scheme 15 Some complex molecules derived from perimidine 

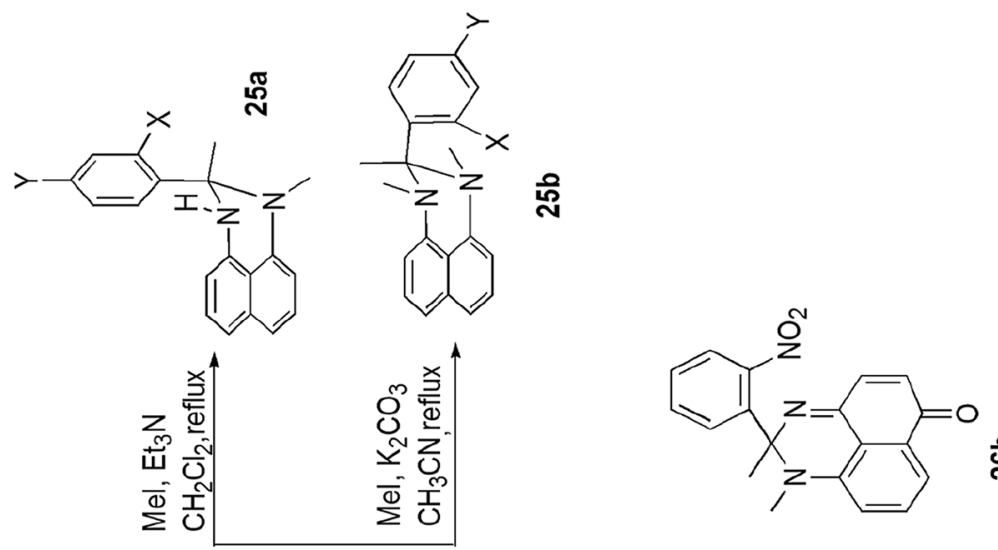

영 웅
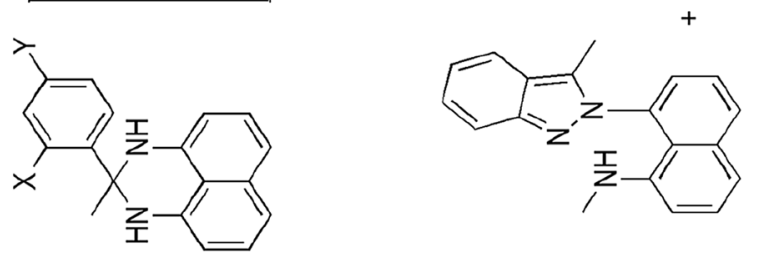

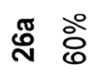
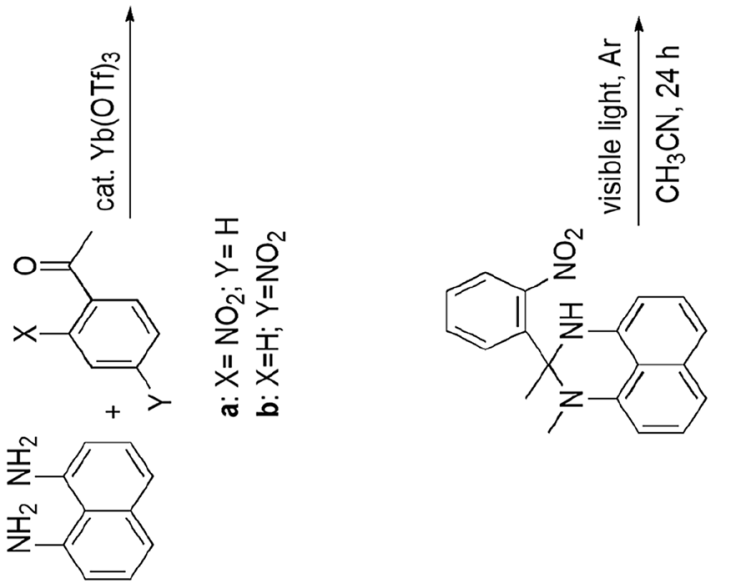

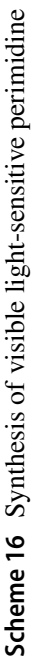


Scheme 17 Synthesis of visible light-sensitive perimidine

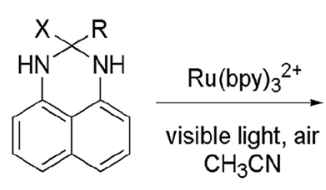

$\mathrm{X}: \mathrm{H}, \mathrm{CH}_{3}$<smiles>[X]C1([R])N=C2C=CC(=O)c3cccc(c32)N1</smiles>

major

27a<smiles>[X]C1([R])N=C2C(=O)C=Cc3cccc(c32)N1</smiles>

minor

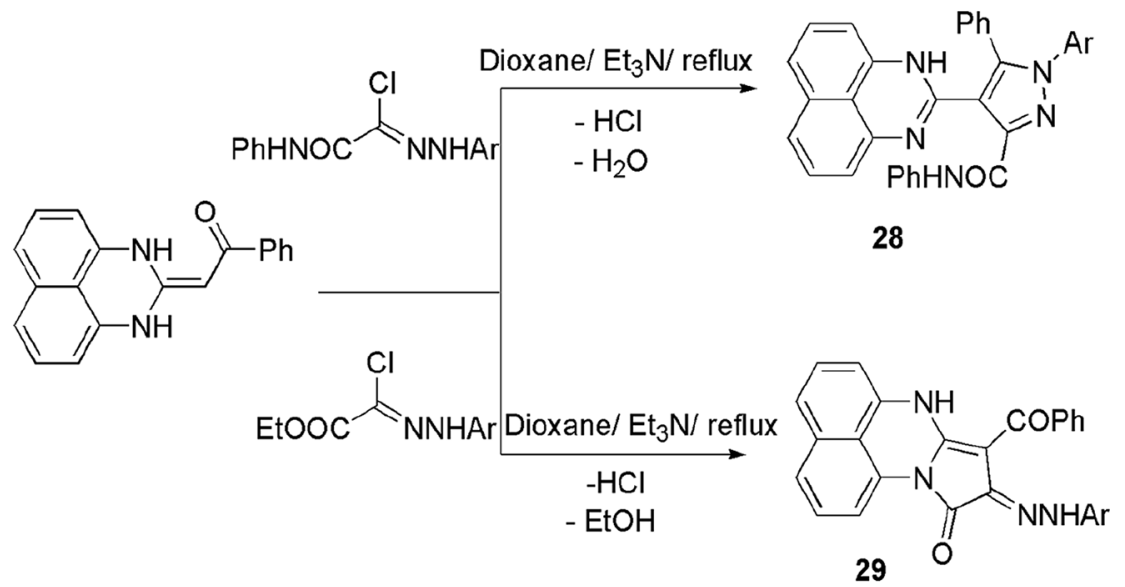

Scheme 18 Site- and regioselective reaction of hydrazonoyl chlorides with perimidine ketene aminal derivative

and aerobic oxidation. The $\mathrm{Ru}(\mathrm{bpy})_{3}{ }^{2+}$ catalyst was easily recovered and reused in further synthesis (Scheme 17).

Farghaly and colleagues [144] reported a new technique to synthesize a range of site- and regioselective perimidine derivatives $\mathbf{2 8 , 2 9}$ from perimidine, ketene aminal, and hydrazonoyl chlorides by refluxing under dioxane solvent and $\mathrm{Et}_{3} \mathrm{~N}$ catalyst. The afforded products were site- and regioselective, according to applied hydrazonyl chlorides, i.e., $N$-aryl 2-oxo-2-phenylaminoethane-hydrazonoyl chlorides produced pyrazolyl perimidines while ( $N$-arylhydrazono)-chloroacetates afforded pyrrolo[1,2-a]perimidines. All of the synthesized compounds underwent antimicrobial screening and exhibited moderate activity against $E$. coli and $S$. aureus and were found inactive against A. flavus and C. albicans (Scheme 18).

Furthermore, Farghaly et al. [145] stated a practical and convenient route for the synthesis of a library of 2-(5-substituted-pyridazine-3,6-dion-4-yl)perimidine derivatives 30 from the condensation of (1H-perimidin-2-yl) acetic acid hydrazide with ethyl $\mathrm{N}$-arylhydrazonochloroacetate in the presence of triethylamine and dioxane solvent. The entire range of derivatives exhibited promising antimicrobial activities against both fungal and bacterial strains. The presence of 
pyridazine moiety and ester and phenylazo group at the 4th position increased their activity (Scheme 19).

Shawali and colleagues [146] introduced a unique method for the selective synthesis of 2-(pyrazoliden-4-yl) perimidines 31a and pyrrolo[1,2-a] perimidines 31b from the reaction of ethyl 2(3H)-permidinylideneacetate with $C$-aryl- $N$-arylmethanehydrazonoyl and $C$-ethoxycarbonyl- $N$-arylmethanehydrazonoyl chlorides, respectively, in the presence of dioxane solvent and triethylamine catalyst under reflux conditions (Scheme 20).

Substituted pyrrolo [1,2-a]perimidin-10-ones 32 were prepared from perimidine analogs and maleic anhydride and their structural and energetic properties were studied by Koca and coworkers [147]. From the NMR structural studies, their two tautomeric forms $\mathbf{3 2}(\mathbf{a}, \mathbf{b})$, enamine and imine, were found and ab initio HF, HOMO, and LUMO energies and DFT (B3LYP) theory findings revealed that the enamine form was more stable than the imine form due to $\mathrm{H}$-bonding and resonance (Scheme 21).

A novel range of benzoperimidones were developed from perimidines under Ullman conditions and further $\mathrm{N}$-alkylated with different reagents by Baranov et al. [148] to obtain high yields and purity.

Filatova and coauthors [149] developed a novel and efficient route for the preparation of an extensive range of multisubstituted alkynyl derivatives of perimidones from mono-halogenated perimidones and corresponding acetylenes using a combination of catalyst $\mathrm{Pd}_{2} \mathrm{dba}_{3} / \mathrm{PPh}_{3} / \mathrm{CuI} / \mathrm{K}_{2} \mathrm{CO}_{3} / \mathrm{DMF}$ in 66 to $77 \%$ yields. Authors also explained the properties of synthesized compounds and their comparative pericyclization properties with 1,8-dialkynylnaphthalenes derivatives.
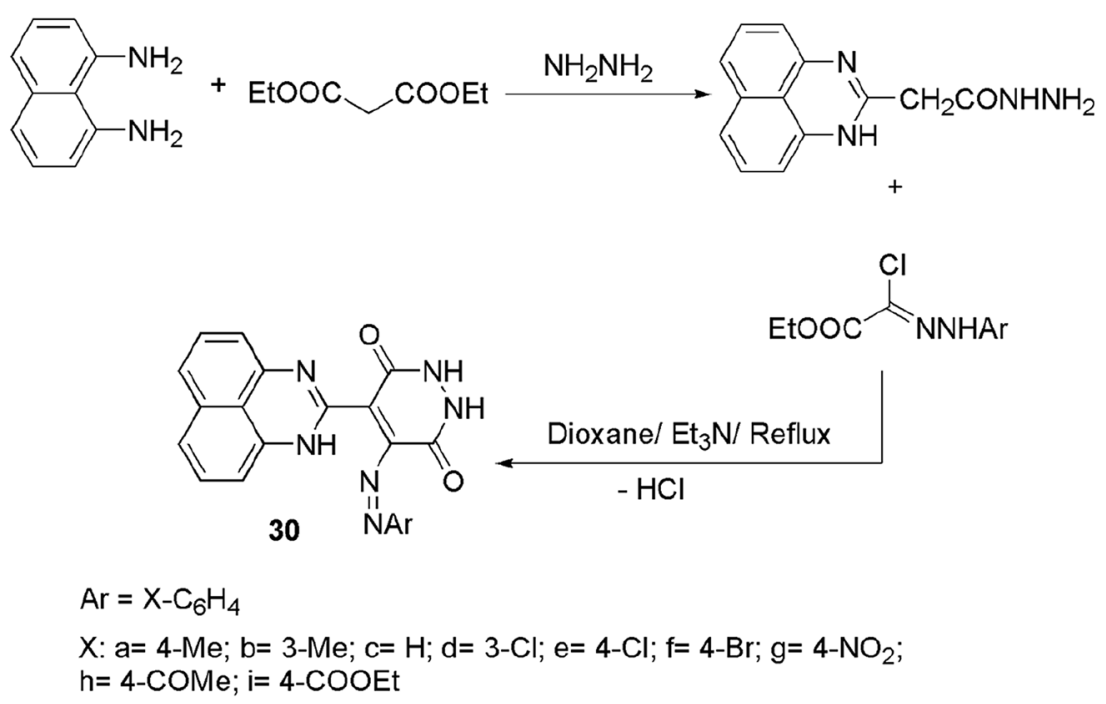

Scheme 19 Synthesis of 2-(5-substituted-pyridazine-3,6-dion-4-yl)perimidine derivatives 


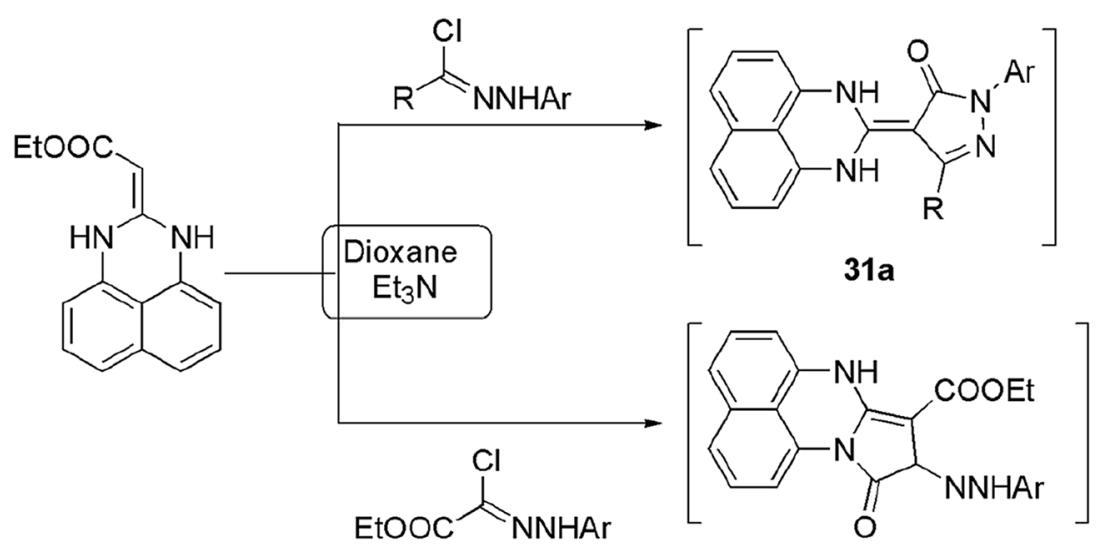

31b

Scheme 20 Chemoselective reactions of hydrazonoyl halides with ethyl 2(3H)-peridinylideneacetate

Scheme 21 Two tautomeric forms of pyrrolo[1,2-a] perimidin-10-ones

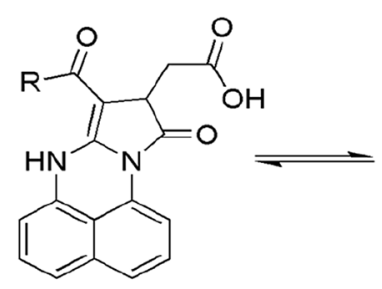

$32 \mathbf{a}$<smiles>[R]C(=O)C1C2=Nc3cccc4cccc(c34)N2C(=O)C1CC(=O)O</smiles>

32b

"Tightening effect" controlled the orientation of perialkynyl groups and moved them away from each other.

Huang and coworkers [150] developed an innovative and chemoselective synthesis from perimidines to produce 13-aminoisoquinolino[2,1- $a$ ]perimidine-12-carboxylate derivatives 33 by $\alpha$-arylation of cynoacetate catalyzed by combination of CuI, L-proline, and $\mathrm{NaHCO}_{3}$ in the presence of DMF at $60{ }^{\circ} \mathrm{C}$ (Scheme 22).

\subsection{Miscellaneous Applications}

Photophysical and electroluminescent properties of perimidine derivatives have been studied by researchers in various solvents, viz., cyclohexane, acetonitrile, dioxane, EtOH, DMSO, etc., by determining their quantum yields, Stokes shift, and radiative constant. Different techniques and studies like absorption and fluorescence spectral studies and excited state intramolecular proton transfer (ESIPT) mechanism were used to determine these characteristics. Perimidines molecules have strong photoactivity, which was affected by wavelength, substitution 


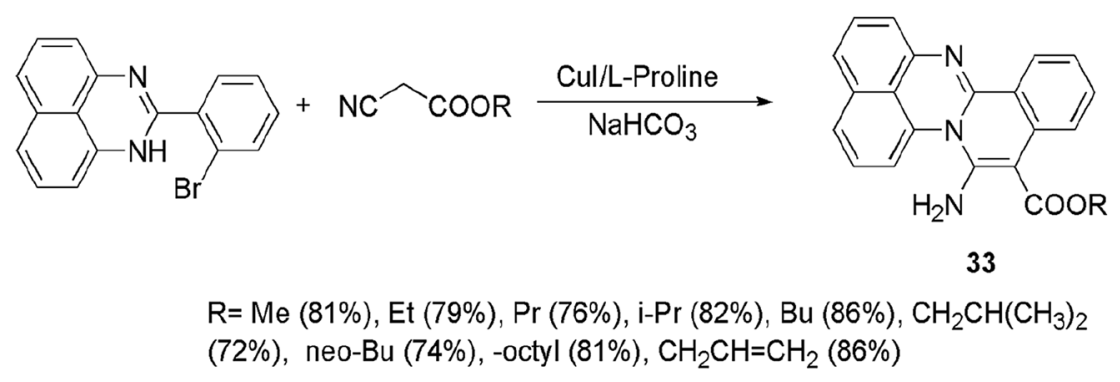

Scheme 22 Copper-catalyzed chemoselective synthesis of 13-aminoisoauinolino [2,1-a]perimidine12-carboxylate

patterns, H-bonding, solvents, and dipole-dipole interaction. In 1997, Carlos de Valle [151] displayed the photophysical properties of perimidine and found that all selected molecules exhibited high photostability against UV light. Further, a novel class of perimidine-squarylium dyes $\mathbf{3 4}$ was designed, synthesized, and their photostability was also studied by Kim et al. [152]. All dyes showed absorption at the near-infrared region $(800 \mathrm{~nm})$ and PPP-MO calculation revealed that the bathochromic properties were controled by the EDG of the heteroaromatic ring. The aggregation behavior of dyes in DMSO- $\mathrm{H}_{2} \mathrm{O}$ solution was studied and it was found that aggregation was influenced by the terminal groups of these dyes (Scheme 23).

In 2007, Davis and coauthors [153] synthesized novel spirodimers of perimidine 35 (Scheme 23) and evaluated the photochromism properties and the photoswitching between open-ring and closed-ring isomers. Here, the authors applied two modes of switching - photo thermal $(365 \mathrm{~nm})$ and pure visible $(500-700 \mathrm{~nm})$, and the results exhibited that the ring-open form of perimidine was depicting the fluorescent effect. Here, the effect of substitution of aliphatic and aromatic group was also evaluated. These results proved helpful in different areas like sensors, optical switches, and other fluorescence-switching devices.

Varsha et al. [154] designed and synthesized two novel perimidine derivatives, 36a, 36b (Scheme 23), and evaluated their crystal structure and fluorescent and antimicrobial properties. These two novel compounds were prepared from NDA and 4-hydroxy-3-methoxy benzaldehyde using methanol in good yields and their photo physical properties were also evaluated in different solvents through UV-Vis absorption study. The antibacterial screening results demonstrated that both compounds were highly potent towards Staphylococcus aureus.

Mahapatra et al. [155] synthesized a novel perimidine-boron complex 37 and evaluated them for selective detection of fluoride ion from fluorometric and colorimetric method. Another new anion receptor combined with 1-methyl-1 $\mathrm{H}$-perimidine 38 was synthesized by Pandian et al. [156]. This perimidine receptor was complexed with $\mathrm{Cl}^{-}, \mathrm{Br}^{-}, \mathrm{NO}_{2}^{-}$, and $\mathrm{I}^{-}$anions through hydrogen bonding. The strength of hydrogen bonding varied with variation in anion, i.e., sensitivity of dyes increased parallel with the basicity of anion (Scheme 23). 

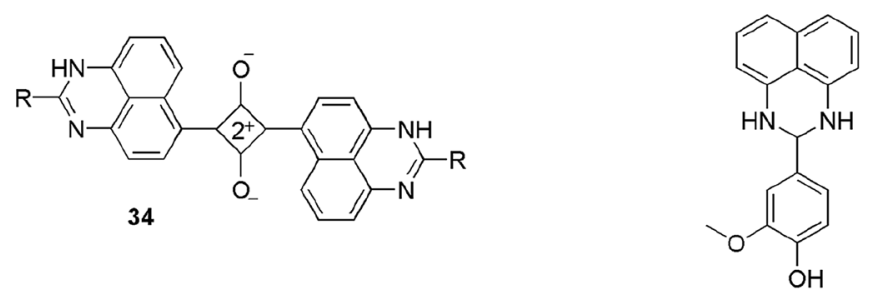<smiles>c1cc2c3c(cccc3c1)NC(c1cnc3ccccc3n1)N2</smiles><smiles>CCc1nc2c3c(cccc3n1)C=CC2(Nc1ccccc1)Nc1cccc2cccc(O)c12</smiles><smiles>C1CCCCCC1</smiles><smiles>CCc1cc2cccc3c2c(n1)C=C/C3=N\c1cccc2cccc(N)c12</smiles>
35(open)

$36 a$

$36 \mathrm{~b}$<smiles>CC1=CC2=Nc3cccc4cccc(c34)N2B(F)O1</smiles><smiles></smiles><smiles>c1cc(C2Nc3cccc4cccc(c34)N2)cc(C2Nc3cccc4cccc(c34)N2)c1</smiles>

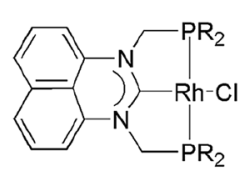

40

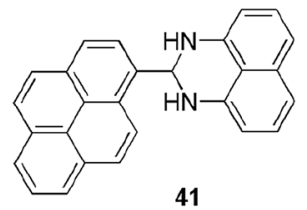

41

Scheme 23 Multifarious applicable synthesized perimidine molecules

Roy and coauthors [157] synthesized a perimidine-based chemo-sensor 39 (Scheme 23) and evaluated it as an antioxidant and studied its binding properties with calf-thymus DNA. This chemo-sensor selectively detected aqueous $\mathrm{Cu}^{2+}$ ion from naked eyes due to strong binding interaction. This 1,3-bis(2,3-dihydro- $1 H$-perimidin-2-yl)benzene showed high free-radical scavenging ability and also established good binding with calf-thymus DNA helix.

He and coworkers [158] designed two perimidine derivatives and explored them as corrosion inhibitors in an acidic medium. The amino group-substituted perimidines showed higher inhibition due to the presence of a large $\pi$-bonded system, which controled interaction energy between the iron surface and molecules. These results were scrutinized from various computational and electrochemical data.

Lam and coworkers [159] developed a new perimidine-based catalyst 40 (Scheme 23) for selective formylation and methylation of primary and secondary amines. These $\mathrm{N}$-heterocyclic carbenes stabilized metal complexes during the catalysis process. Here, rhodium-derived perimidinylidene complex $\left[\mathrm{RhCl}\left\{\mathrm{C}\left(\mathrm{NCH}_{2} \mathrm{P}\right.\right.\right.$ 
$\left.\mathrm{R}_{2}\right)_{2} \mathrm{C}_{10} \mathrm{H}_{6}$ \}] catalyzed amines under mild conditions in the presence of $\mathrm{CO}_{2}$. The authors also studied the effect of temperature, solvent, and amount of hydrosilane added in the procedure to control the reaction process.

Chakraborty and coworkers [160] designed and synthesized a novel and multifunctional pyrimidine-pyrene-based heterocycle as colorimetric sensor, antioxidant, and exhibited ligand-protein interaction. Dihydroperimidine [2-(pyren-1-yl)-2,3-dihydro-1H-perimidine] 41 (Scheme 23) manifested aggregation-induced emission and worked as a good luminogen in the dilute solution of acetonitrile-water. It worked as a turn-off-fluorescence response and a selective sensor for $\mathrm{Cu}^{+2}$ ion in aqueous phase up to $37.5 \mathrm{nM}$, which was easily detectable with naked eyes. Further, it showed 5.9 times more radical scavenging ability as compared to L-ascorbic acid and also displayed interaction with bovine serum albumin protein in Tris $-\mathrm{HCl}$ buffer solution.

\section{Discussion and future perspective}

From detailed study, it was concluded that numerous new and emerging approaches have been established in the field of perimidine synthesis and applications. The toolbox looks prosperous and versatile but still many challenges are present that need solicitous attention of scientists. Most of the synthetic methods used NDA and carbonyl compounds as starting materials with variation in the environmental conditions. We need to explore other synthetic routes using different starting materials to develop versatility in this field. Despite their wide utility, most of the methods have some limitations like special instrumentation, use of hazardous regents and solvents, non-recyclable catalyst, low yields, tedious workup, and waste generation, etc. At the present time, the most important concern is eco-benign and green synthesis using different catalysts like nanoparticles, ionic liquids under MWI, ultrasonication, ball-milling avoiding high temperature, and harsh solvents. Researchers should focus on pathways that are novel, safe, economically cheaper, have high atom economy, high selectivity, reduce waste generation, have a simple workup process, avert chromatographic separation, and follow green matrices. Moreover, scientists should focus on water-based reactions due to their mild environment, simple work-up procedure, and reducing waste generation in addition to lowering the impact of toxic and hazardous solvents. Several researchers are working in this direction to develop diversity-oriented perimidine nucleus through solvent-free, catalyst-free, and onwater synthesis to reduce negative impact on the environment and human beings.

Since perimidines are vital and progressively growing multidisciplinary research arena and bear unique characteristics and properties. Therefore, researchers should work on detailed insights of their structural skeleton to increase their applicability in physical, material science, and nanotechnology. Though a plethora of work has been done on the biologic activity of perimidine composites, designing a new perimidine framework for novel drug candidates is, however, an uphill process. We should develop more structurally modified clinical drugs to overcome their weakness and introduce new groups and fragments to invent multi-target drugs. An important strategy is to plan further structure-activity relationships (SAR) to determine their 
special interaction with particular amino acids and proteins and also follow computational in silico screening like docking studies that may display detailed information about which part of the molecule is most effective against particular disease. In our opinion and need of the era, the most critical issue is the development of sustainable synthesis from laboratory stage to industrial level and in-depth study of their mechanism, physiochemical properties, interaction with various ranges of light waves, and bonding ability with diverse molecules via opening the door of green chemistry, which shall lead to fundamental innovation in multifarious areas of perimidine. Furthermore, this article gives an up-to-date overview for further studies in chemistry of perimidines and shall attract and encourage scientists for new and efficient discoveries.

\section{Conclusions}

After a sluggish start half a century ago, perimidines have displayed an upsurge within the past two decades and have developed as an independent zone in heterocyclic chemistry. This research area experienced more vivid renaissance and more exciting research work done as it has integrated different fields via several advantages that is the demand of present conditions of our society. The unique features of perimidines, especially electronic behavior, allow for various opportunities in pharmaceutical, industrial, and synthetic areas. As per literature study, this will be the only review that critically discusses synthesis and applications of perimidines after 1981. This review is envisioned to highlight the contribution of perimidines in synthetic, medicinal, and other fields, which make them a versatile motif in organic chemistry. In this article, we have systematically reviewed the various synthetic approaches of perimidines using different environmental conditions such as acid-catalyzed, nano-catalyzed, and MW-assisted synthesis, etc., and compiled the applications of perimidine derivatives in life sciences, pharmaceutical sciences, and chemical industries. The significant advantages and limitations of synthetic methods of perimidines have also been discussed in order to emphasize future research trends with less hazardous reaction conditions, enhanced green parameters, high yields with high selectivity, and avoiding use of hazardous precursors etc. Keeping the aforementioned in mind, this article shall play an important role for researchers in developing novel, eco-friendly, and efficient synthetic routes for the synthesis of bioactive and industrially applicable perimidines.

Acknowledgements The authors are grateful to Department of Chemistry, M.L.S.U. Udaipur (Raj.), India, for providing necessary laboratory and library facilities. N. Sahiba is grateful to the Council for Scientific and Industrial Research (CSIR) (file no. 09/172(0088)2018-EMR-I) New Delhi, for the award of Junior Research Fellowship as financial support. We would like to extend our sincere thanks to the unsigned reviewers for their invaluable and insightful suggestions.

\section{Compliance with Ethical Standards}

Conflict of interest The authors confirm that this article has no conflicts of interest. 


\section{References}

1. O'Brien JJ, Campoli-Richards DM (1989) Acyclovir. An updated review of its antiviral activity, pharmacokinetic properties and therapeutic efficacy. Drugs 37(3):233-309

2. Elce M, Dearden CE, Matutes E, Garcia-Talavera J, Rohatiner AZS, Johnson SAN, O'Connor NTJ, Haynes A, Osuji N, Forconi F, Lauria F, Catovsky D (2009) Long-term follow-up of 233 patients with hairy cell leukaemia, treated initially with pentostatin or cladribine, at a median of 16 years from diagnosis. Br J Haematol 145(6):733-740

3. Arora P, Arora V, Lamba HS, Wadhwa D (2012) Importance of heterocyclic chemistry: a review. Int J Pharm Sci 3(9):2947-2954

4. Walkembach J, Brüss M, Urban BW, Barann M (2005) Interactions of metoclopramide and ergotamine with human 5-HT3A receptors and human 5-HT reuptake carriers. Br J Pharmacol 146(6):543-552

5. Rudi A, Shmul G, Benayahu Y, Kashman Y (2006) Sinularectin, a new diterpenoid from the soft coral Sinularia erecta. Tetrahedron Lett 47(17):2937-2939

6. Joule JA (2016) Natural products containing nitrogen heterocycles some highlights 1990-2015. Adv Heterocycl Chem 119:81-106

7. Daly JW, Garraffo HM, Spande TF, Decker MW, Sullivan JP, Williams M (2000) Alkaloids from frog skin: the discovery of epibatidine and the potential for developing novel non-opioid analgesics. Nat Prod Rep 17(2):131-135

8. de Aguiar A (1874) Ueber einige Abkömmlinge des $\alpha$ - und $\beta$-diamidonaphtalins. Ber Dtsch Chem Ges 7:309-319

9. Sachs F (1909) Ueber ringschlüsse in peristellung der naphtalinreihe. Justus Liebigs Ann Chem 365(1):53-134

10. Jeffreys RA (1955) Perimidine dyes and intermediates. J Chem Soc 2394-2397. https://doi. org/10.1039/JR9550002394

11. Bazinet P, Yap GPA, Richeson DS (2003) Constructing a stable carbene with a novel topology and electronic framework. J Am Chem Soc 125(44):13314-13315

12. Verlinden K, Ganter C (2014) Converting a perimidine derivative to a cationic $N$-heterocyclic carbene. J Organomet Chem 750:23-29

13. Azam M, Warad I, Al-Resayes SI, Alzaqri N, Khan MR, Pallepogu R, Dwivedi S, Musarrat J, Shakir M (2013) Synthesis and structural characterization of Pd(II) complexes derived from perimidine ligand and their in vitro antimicrobial studies. J Mol Struct 1047(1):48-54

14. Azam M, Warad I, Al-Resayes S, Zahin M, Ahmad I, Shakir M (2012) Syntheses, physicochemical studies and antioxidant activities of transition metal complexes with a perimidine ligand. Anorg Allg Chem 638(5):881-886

15. Bassyouni FA, Abu-Bakr SM, Hegab KH, El-Eraky W, El-Beih AA, Rehim MEA (2012) Synthesis of new transition metal complexes of $1 H$-perimidine derivatives having antimicrobial and anti-inflammatory activities. Res Chem Intermed 38:1527-1550

16. Braña MF, Garrido M, LopezRodriguez ML, Morcillol MJ, Alvarez Y, Valladares Y, Klebe G (1990) Synthesis, structure and cytostatic activity of a series of 2-substituted perimidines. Eur J Med Chem 25(3):209-215

17. Fan SY, Xu HT, Li QG, Fang DM, Yu WH, Xiang SK, Hu P, Zhao KQ, Feng C, Wang BQ (2019) Discotic mesogens based on triphenylene-fused benzimidazole or perimidine: facile synthesis, mesomorphism, optical properties and self-assembly. Liq Cryst Liq. https://doi. org/10.1080/02678292.2019.1704898

18. Alıcı B, Özdemir I, Karaaslan K, Çetinkaya E, Çetinkaya B (2005) Synthesis and catalytic properties of 1-alkylperimidineruthenium (II) complexes. J Mol Catal A Chem 231(1-2):261-264

19. Choi G, Tsurugi H, Mashima K (2013) Hemilabile $N$-xylyl- $N$ '-methylperimidine carbene iridium complexes as catalysts for $\mathrm{C}-\mathrm{H}$ activation and dehydrogenative silylation: dual role of $\mathrm{N}$-xylyl moiety for ortho-C-H bond activation and reductive bond cleavage. $\mathrm{J}$ Am Chem Soc 135(35):13149-13161

20. Akıncı PA, Gülcemal S, Kazheva ON, Alexandrov GG, Dyachenko OA, Çetinkaya E, Çetinkaya B (2014) Perimidin-2-ylidene rhodium (I) complexes; unexpected halogen exchange and catalytic activities in transfer hydrogenation reaction. J Organometal Chem 765:23-30 
21. Jakubek M, Kejík Z, Kaplánek R, Veselá H, Sýkora D, Martásek P, Král V (2018) Perimidinebased synthetic receptors for determination of copper(II) in water solution. Supramol Chem 30(3):218-226

22. Morita Y, Suzuki S, Fukui K, Nakazawa S, Kitagawa H, Kishida H, Okamoto H, Naito A, Sekine A, Ohashi Y, Shiro M, Sasaki K, Shiomi D, Sato K, Takui T, Nakasuji K (2008) Thermochromism in an organic crystal based on the coexistence of $\sigma$-and $\pi$-dimers. Nat Mater 7(1):48-51

23. Malherbe RF (1983) 2,3-Dihydroperimidines as antioxidants for lubricants. US Patent. US 4,389,321. Jun. 21

24. Hsueh SY, Cheng KW, Lai CC, Chiu SH (2008) Efficient solvent-free syntheses of [2]- and [4] rotaxanes. Angew Chem Int Ed Engl 47(23):4436-4445

25. Sahiba N, Sethiya A, Soni J, Agarwal DK, Agarwal S (2020) Saturated five-membered thiazolidines and their derivatives: from synthesis to biological applications. Top Curr Chem 34:378-468

26. Agarwal S, Gandhi D, Kalal P (2017) Benzothiazole: a versatile and multitargeted pharmacophore in the field of medicinal chemistry. Lett Org Chem 14(10):729-742

27. Prajapat P, Agarwal S (2018) Benzimidazole scaffold as a versatile biophore in drug discovery: a review. Chem Biol Interface 8(1):1-10

28. Soni J, Sethiya A, Sahiba N, Agarwal S (2019) Contemporary progress in the synthetic strategies of imidazole and its biological activities. Curr Org Synth 16(8):1078-1104

29. Sethiya A, Sahiba N, Soni J, Gandhi D, Agarwal S (2018) Contemporary progress in the synthesis and reaction of 2-arylbenzothiazole: a review. Curr Org Chem 22:2599-2634

30. Teli P, Sethiya A, Agarwal S (2019) An insight view on synthetic protocol, mechanistic and biological aspects of biscoumarin derivatives. Chemistryselect 4(47):13772-13787

31. Richmond JH (1958) Six-membered heterocyclic nitrogen compounds with three condensed rings. Academic Press, New York, p 518

32. Pozharskii AF, Dal'nikovskay VV (1981) Perimidines. Russ Chem Rev 50(9):1559-1600

33. Nyulászi L, Pasinszki T, Réffy J, Veszprémi T, Fabian J, Thiel W (1990) Photoelectron spectroscopic investigation of perimidine derivatives. Struct Chem 1:367-370

34. Deady LW, Rodemann T (1998) Synthesis of perimidine and fused perimidine derivatives from reaction of 1,8-naphthalene diamine with an iminoisocoumarine. J Heterocycl Chem 35(6):1417-1419

35. Yavari I, Adib M, Jahani-Moghaddam F, Bijanzadeh HR (2002) Vinylphosphonium salt mediated simple synthesis of 7-oxo-7H-pyrido[1,2,3-cd]perimidine derivatives. Dynamic NMR spectroscopic study of prototropic tautomerism in ethyl $1 H$-perimidine-2-carboxylate. Tetrahedron 58(34):6901-6906

36. Popp FD, Catala A (1964) Synthesis of potential antineoplastic agents. XI. Some 2-Ary 1-2,3-di hydro- $H$-perimidines and a perimidine mustard. J Heterocycl Chem 1(2):108-109

37. Morita Y, Aoki T, Fukui K, Nakazawa S, Tamaki K, Suzuki S, Fuyuhiro A, Yamamoto K, Sato K, Shiomi D, Naito A, Takui T, Nakasuji K (2002) A new trend in phenalenyl chemistry: a persistent neutral radical, 2,5,8-tri-tert-butyl-1,3-diazaphenalenyl, and the excited triplet state of the gable syn-dimer in the crystal of column motif. Angew Chem Int Ed Engl 41(10):1793-1798

38. Li Z, Deng W (2011) Synthesis, characterization, crystal structure and DFT studies on 1',3'-dihydrospiro[fluorene-9,2'-perimidine]. Spectrochimica Acta A Mol Biomol Spectrosc 82(1):56-62

39. Ghorbani MH (2012) 2-Methylsulfanyl-1H-perimidin-3-ium iodide. Acta Crystallogr Sect E Struct Rep 68(Pt9):2605. https://doi.org/10.1107/S1600536812033697

40. Alkorta I, Blanco F, Elguero J, Claramunt RM (2010) The azido-tetrazole and diazo-1,2,3-triazole tautomerism in six-membered heteroaromatic rings and their relationships with aromaticity: azines and perimidine. Tetrahedron 66(15):2863-2868

41. Grimmer CD (2017) Crystal structure of phenyl(2-phenyl-2,3-dihydro-1H-perimidin-2-yl)methanone, $\mathrm{C}_{24} \mathrm{H}_{18} \mathrm{~N}_{2} \mathrm{O}$. Kristallogr Z NCS 232(2):289-290

42. Butkute R, Lygaitis R, Gudeika D, Grazulevicius JV, Obushak MD (2016) Synthesis and properties of glass-forming 2-substituted perimidines. Mol Cryst Liq Cryst 640(1):1-12

43. Starshikovand NM, Pozharski FT (1973) Synthesis of 2-(5-halogeno-2-furyl)-2,3-dihydroperimidines. Chem Heterocycl Compd 9:922-924 (Translated from Khhniya Geterotsiklicheskikh Soedinenii)

44. Llamas-Saiz AL, Foces-Foces C, Sanz D, Claramunt RM, Dotor J, Elguero C, Catalán J, del Valle JC (1955) 2-Arylperimidine derivatives. Part 1. Synthesis, NMR spectroscopy, X-ray crystal and molecular structures. J Chem Soc Perkin Trans 2:1389-1398 
45. Mosher WA, Serridge PM, Lipp DW (1972) Reactions of 2-acyl-3(2H)-benzofuranones with hydrazines and diamines. J Org Chem 37(15):2402-2405

46. Maquestiau A, Berte L, Mayence A, Eynde JJV (1991) An improved one-pot method for the preparation of 2-substituted $1 H$-perimidines. Synth Commun 21(21):2171-2180

47. Ozeryanskii VA, Filatova EA, Sorokin VI, Pozharskii AF (2001) Peri-Naphthylenediamines. 31. Study of interconversion of 2,3-dihydroperimidines and 1,8-bis(dialkylamino)naphthalenes. Convenient synthesis of 1,2,2,3-tertramethyl-2,3-dihydroperimidines and a monoisopropyl analog of the "proton sponge". Rus Chem Bull 50(5):846-853

48. Paragamian V, Baker MB, Puma BM, Reale J Jr (1968) A study of the synthesis and some reactions of perimidines. J Heterocycl Chem 5(5):591-597

49. Honda K, Nakanishi H, Yabe A (1983) Reaction of 1,8-naphthalenediamine with dimethyl and diethyl acetylenedicarboxylates. Bull Chem Soc Jpn 56(8):2338-2340

50. Smellie IAS, Fromm A, Moggach SA, Paton RM (2011) Synthesis and structure of 2-pyransoylperimidines. Carbohydr Res 346(1):43-49

51. Minkin VI, Zhdanov YA, Sadekov ID, Raevskii OA, Garnovskii AD (1967) Structure and properties of perimidine and its derivatives. Chem Heterocycl Comp 3(6):1100-1108

52. Norikane Y, Davis R, Nishimura Y, Arai T, Tamaoki N (2009) Drastic solvent effect on thermal back reaction of spiroperimidine photochromic compounds. J Photochem Photobiol A 205(2-3):116-121

53. Hill AF, Ma C, McQueen CMA, Ward JS (2018) Iridium complexes of perimidine-based $N$-heterocyclic carbene pincer ligands via aminal C-H activation. Dalton Trans 47:1577-1587

54. Booysen IN, Ebinumoliseh I, Sithebe S, Akerman MP, Xulu B (2016) Coordination behaviours of perimidine ligands incorporating fused $N$-donor heterocyclics towards rhenium(I) and -(V). Polyhedron 117:755-760

55. Mistol J, Ernst S, Keil D, Hennig L (2015) Structural studies of squaraines containing 2,3-dihydro$1 H$-perimidine terminal groups. Dyes Pigm 118:58-63

56. Bahena EN, Gijón CAF, Fomine S, Alexandrova L, Lagadec RL (2019) Synthesis, characterization, and spectroscopic properties of allylic ruthenium(II) complexes of a highly conjugated perinones. Eur J Inorg Chem 30:3494-3502. https://doi.org/10.1002/ejic.201900615

57. Ozeryanskii VA, Vlasenko MP, Pozharskii AF (2013) 'Proton sponge' amides: unusual chemistry and conversion into superba sic 6,7-bis(dimethylamino)perimidines. Tetrahedron 69:1919-1929

58. Pozharskii AF, Kashparov IS, Andreichikov YP, Buryak AI, Konstantinchenko AA, Simonov AM (1971) Heterocyclic analogs of pleiadiene. VII. Tautomerism of 2-amino derivatives of perimidine, aceperimidine, and their imidazole analogs. Chem Heterocycl Compd 7:752-758 (Translated from Khimiya Geterotsiklicheskikh Soedinenii, No. 6, pp. 807-813, June, 1971)

59. Posharshii AF, Kashparov IS, Simonov AM (1968) Perimidine in the chichibabin reaction. Chem Heterocycl Compd 4(1):142

60. Kharlanov V (1999) Photophysics of photochromic spiroperimidinecyclohexadienone. J Photochem Photobiol A 122(3):191-197

61. Filatova EA, Borovlev IV, Pozharskii AF, Starikova ZA, Vistorobskii NV (2000) Trifluoromethylperimidines with electron-withdrawing groups at the6(7)-position: a case of extremely hindered annular prototropy. Mendeleev Commun 10(5):178-180

62. Pozharskii AF, Smirnova LP, Belyashova AI, Zatsepina NN, Tupitsyn IF (1979) Heterocyclic analogs of pleiadiene. 43. Metalation of the 2-methylgroup in perimidines. Kinetic acidities of 2-methylderivatives of perimidine and condensed imidazole systems. Chem Heterocycl Compd 15:785-787 (Translated from Khimiya Geterotsiklicheskikh Soedinenii, No. 7, pp. 961-963, July, 1979)

63. Espenbetov AA, Pozharskii AF, Struchkov YT, Suslov AN (1985) Effect of geminal substituents on dehydrogenation of dihydro derivatives of nitrogen heterocycles. 2,3-Dihydroperimidines and benzimidazolines. Chem Heterocycl Compd 21:814-821 (Translated from Khimiya Geterotslkllcheskikh Seedinenii, No. 7, pp. 977-985, July, 1985)

64. Aksenov AV, Lyakhovnenko AS, Perlova TS, Aksenova IV (2011) Ammonium nitrate in acetic acid, an efficient reagent for the nitration of perimidines and the one-pot synthesis of 6(7)-aminoperimidines. Chem Heterocycl Compound 47(2):245-246 (Translated from Khimiya Geterotsiklicheskikh Soedinenii, No. 2, pp. 304-305, February, 2011)

65. Eynde JJV, Mayence A, Maquestiau A, Anders E (1992) Novel syntheses of heterocycles with $n$-(1-haloalkyl)azinium halides. Part 4. An unexpected one-pot preparation of $1 H$-perimidines. Synth Commun 22(21):3141-3150 
66. Drusvyatskaya SK, Lopatin BV, Bekhli AF, Krotov AI, Naidenova AS (1976) Vinyl derivatives of perimidine. Pharm Chem J 10:614-617

67. Liu KC, Huang HS (1989) Synthesis of ethyl 4(1H)-oxopyrimido[1,2-a]perimidine-3-carboxylate. Arch Pharm 322(5):303-304

68. Gandhi D, Agarwal S (2018) Urea nitrate catalyzed synthesis of novel 2-arylbenzothiazole derivatives using the grindstone technique. Heterocycl Commun 24(6):307-310

69. Song H, Xing C, Li B, Shen W (2016) Spherical carbon with $\mathrm{SO}_{3} \mathrm{H}$ groups as an efficient solid acid catalyst for 2,4,5-triphenyl-imidazole synthesis. Chemistryselect 1(2):301-308

70. Zendehdel M, Mobinikhaledi A, Alikhaniani H, Jafari N (2010) Preparation of heteropoly acid/ porous hybrid materials and investigation of their catalytic behavior in the synthesis of perimidine. J Chin Chem Soc 57(4A):683-689

71. Phadtare SB, Vijayraghavan R, Shankarling GS, Macfarlane DR (2012) Efficient synthesis of 2,3-dihydro- $1 H$-perimidine derivatives using $\mathrm{HBOB}$ as a novel solid acid catalyst. Aust $\mathrm{J}$ Chem 65(1):86-90

72. Koca I, Üngören ŞH, Kıbrıza IE, Yılmaz F (2012) The synthesis of new pyrrolo[1,2-a]perimidin10-one dyes via two convenient routes and its characterizations. Dye Pigm 95(2):421-426

73. Prakash GKS, Paknia F, Narayan A, Mathew T, Olah GA (2013) Synthesis of perimidine and 1,5-benzodiazepine derivatives using tamed Brønsted acid, $\mathrm{BF}_{3}-\mathrm{H}_{2} \mathrm{O}$. J Fluor Chem 152:99-105

74. Alinezhad H, Zare M (2013) Sulfonated ordered nanoporous carbon as an efficient solid catalyst for the synthesis of perimidine derivatives. J Chil Chem Soc 58(3):1840-1841

75. Azeez HJ, Salih KM (2014) Synthesis, characterization and biological activity of 2-aryl-2,3-dihydro- $1 H$-perimidine. Res Pharm Biotech 5(1):1-6

76. Patil VV, Shankarling GS (2014) A metal free, eco-friendly protocol for the synthesis of 2,3-dihydro- $1 H$-perimidines using commercially available Amberlyst 15 as a catalyst. Catal Commun 57:138-142

77. Bodaghifard MA, Ahadi N (2016) Sulfamic acid: a green and efficient catalyst for synthesis of mono-, bis-, and spiro-perimidines. Iran J Catal 6(4):377-380

78. Patil VD, Patil KP, Sutar NR, Gidh PV (2017) Phenyl boronic acid promoted efficient synthesis of perimidine derivatives under mild condition. Chem Int 3(3):195-201

79. Behbahani FK, Golchin FM (2017) A new catalyst for the synthesis of 2-substituted perimidines catalysed by $\mathrm{FePO}_{4}$. J Taibah Univ Sci 11(1):85-89

80. Shelke PB, Mali SN, Chaudhari HK, Pratap AP (2019) Chitosan hydrochloride mediated efficient, green catalysis for the synthesis of perimidine derivatives. J Heterocycl Chem 56(11):1-7

81. Khopkar S, Shankarling G (2020) Squaric acid: an impressive organocatalyst for the synthesis of biologically relevant 2,3-dihydro-1H-perimidines in water. J Chem Sci 132(31). https://doi. org/10.1007/s12039-019-1735-1

82. Pike SD, Weller AS (2015) Organometallic synthesis, reactivity and catalysis in the solid state using well-defied single-site species. Philos Trans R Soc A 373:20140187

83. Klahn M, Rosenthal U (2012) An update on recent stoichiometric and catalytic C-F bond cleavage reactions by lanthanide and group 4 transition-metal complexes. Organometallics 31(14):1235-1244

84. Zhang J, Zhang SL, Zhang JM (2007) Ruthenium(III) chloride as an efficient catalyst for the synthesis of perimidine derivatives under mild conditions. Chin Chem Lett 18(9):1057-1060

85. Zhang J, Zhang S (2007) Bismuth(III) chloride-promoted efficient synthesis of perimidine derivatives under ambient conditions. Synth Commun 37(15):2615-2624

86. Zhang SL, Zhang JM (2008) Ytterbium(III) triflate as an efficient catalyst for the synthesis of perimidine derivatives under mild conditions. Chin J Chem 26(1):185-189

87. Mobinikhaledi A, Steel PJ (2009) Synthesis of perimidines using copper nitrate as an efficient catalyst. Synth React Inorg M 39(3):133-135

88. Yasaei Z, Mirzaei P, Bazgir A (2010) $\mathrm{InCl}_{3}$-catalyzed efficient synthesis of spiro-perimidine derivatives. C R Chimie 13:1308-1312

89. Belmonte MM, Escudero-Adán EC, Benet-Buchholz J, Haak RM, Kleij AW (2010) Facile synthesis of substituted mono-, di-, tri- and tetra-2-aryl-2,3-dihydro- $1 H$-perimidines. Eur J Org Chem 25:4823-4831

90. Mobinikhaledi A, Bodaghi Fard MA, Sasani F, Amrollahi MA (2013) Molecular iodine catalyzed synthesis of some biologically active dihydroperimidines. Bulg Chem Commun 45(3):353-356

91. Feng BB, Liu JQ, Wang XS (2017) $\mathrm{Cu}(\mathrm{OAc})_{2}$ catalyzed aerobic oxidative dehydrogenation coupling: synthesis of heptacyclicquinolizino[3,4,5,6-kla]perimidines. J Org Chem 82(3):1817-1822 
92. Schwob T, Ade M, Kempe R (2019) A co catalyst permits the direct hydrogenative synthesis of $1 H$ perimidines from a dinitroarene and an aldehyde. Chemsuschem 12(13):3013-3017

93. Gandhi D, Agarwal S (2018) MgONPs catalyzed eco-friendly reaction: a highly effective and green approach for the multicomponent one pot synthesis of polysubstituted pyridines using 2-aminobenzothiazole. J Heterocycl Chem 55(12):2977-2984

94. Gupta S, Ameta C, Punjabi PB (2020) Greener route for microwave enhanced syntheses of bioactive 1,5-benzodiazepines using heterogeneous calcium ferrite/graphene oxide nanocomposite as a novel and sustainable catalyst. J Heterocycl Chem 57(6):2410-2427. https://doi.org/10.1002/ jhet.3957

95. Mobinikhaledi A, Moghanian H, Sasani F (2010) A simple and convenient method for the synthesis of perimidine derivatives catalyzed by nano-silica sulfuric acid. Int J Green Nanotechnol Phys Chem 2(2):P47-P52

96. Kalhor M, Khodaparast N (2013) Use of nano-CuY zeolite as an efficient and eco-friendly nanocatalyst for facile synthesis of perimidine derivatives. Res Chem Intermed 41(5):3235-3242

97. Bamoniri AA, Mirjalili BBF, Saleh S (2018) Nano- $\gamma-\mathrm{Al}_{2} \mathrm{O}_{3} / \mathrm{SbCl}_{5}$ : an efficient catalyst for the synthesis of 2,3-dihydroperimidines. RSC Adv 8(11):6178-6182

98. Mirjalili BBF, Imani $\mathrm{M}(2019) \mathrm{Fe}_{3} \mathrm{O}_{4} @ \mathrm{NCs} / \mathrm{BF}_{0.2}$ : a magnetic bio-based nanocatalyst for the synthesis of 2,3-dihydro-1H-perimidines. J Chin Chem Soc 66(11):1542-1549

99. Amrollahi MA, Vahidnia $\mathrm{F}$ (2018) Decoration of b-CD-ZrO on $\mathrm{Fe}_{3} \mathrm{O}_{4}$ magnetic nanoparticles as a magnetically, recoverable and reusable catalyst for the synthesis of 2,3-dihydro- $1 H$-perimidines. Res Chem Intermed 44:7569-7581

100. Kalhor M, Zarnegar Z (2019) $\mathrm{Fe}_{3} \mathrm{O}_{4} / \mathrm{SO}_{3} \mathrm{H} @$ zeolite-Y as a novel multi-functional and magnetic nanocatalyst for clean and soft synthesis of imidazole and perimidine derivatives. RSC Adv 9:19333-19346

101. Kalhor M, Rezaee-Baroonaghi F, Dadras A, Zarnegar Z (2019) Synthesis of new TCH/Ni-based nanocomposite supported on SBA-15 and its catalytic application for preparation of benzimidazole and perimidine derivatives. Appl Organometal Chem 33(5):e4784

102. Kalhor MS, Zarnegar JF, Mirshokraei SA (2019) $\mathrm{Fe}_{3} \mathrm{O}_{4} @$ zeolite $\mathrm{SO}_{3} \mathrm{H}$ as a magnetically bifunctional and retrievable nanocatalyst for green synthesis of perimidines. Res Chem Intermed 46:821-836

103. Alinezhad H, Ahmadi A, Hajiabbasi P (2019) Application of $\mathrm{SiO}_{2}$ nanoparticles as an efficient catalyst to develop syntheses of perimidines and tetraketones. J Chem Sci 131(34). https://doi. org/10.1007/s12039-019-1607-8

104. Gothelf KV, Hazell RG, Jørgensen KA (1998) Molecular sieve dependent absolute stereoselectivity in asymmetric catalytic 1,3-dipolar cycloaddition reactions. J Org Chem 63(16):5483-5488

105. Heravi MM, Baghernejad B, Oskooie HA (2009) Facile method for the synthesis of combinatorial libraries of benzimidazole, benzothiazole, benzoxazole, perimidine and quinazolinone. Chin $\mathrm{J}$ Chem 27(2):379-383

106. Mobinikhaledi A, Foroughifar N, Basaki N (2009) Zeolite catalyzed efficient synthesis of perimidines at room temperature. Turk J Chem 33(4):555-560

107. Bariwal JB, Ermolat'ev DS, Glasnov TN, Hecke KV, Mehta VP, Meervelt LV, Kappe CO, Van der Eycken EV (2010) Diversity-oriented synthesis of dibenzoazocines and dibenzoazepines via a microwave-assisted intramolecular A3-coupling reaction. Org Lett 12(12):2774-2777

108. Mobinikhaledi A, Foroughifar N, Goli R (2005) Synthesis of some benzotriazole-substituted perimidines. Phosphorus, Sulfur, Silicon 180(11):2549-2554

109. Tokimizu Y, Ohta Y, Chiba H, Oishi S, Fujii N, Ohno H (2011) Direct synthesis of highly fused perimidines by copper(I)-catalyzed hydroamination of 2-ethynylbenzaldehydes. Tetrahedron 67(29):5168-5175

110. Zhu WJ, Ding J, Jiang B, Tu SJ (2013) Highly efficient synthesis of tricyclic perimidines under microwave heating. J Heterocycl Chem 50(S1):E63-E66

111. Shakibaei GI, Samadi S, Ghahremanzadeh R, Bazgir A (2010) Simple and catalyst-free synthesis of oxoindolin-3-yl phosphonates. J Comb Chem 12(2):295-297

112. Aly AA, El-Shaieb KM (2004) Reaction of 1,8-diaminonaphthalene with some selected p-acceptors; prospective optically active non-linear cyanovinylatednaphthalenes as well as synthesis of novel perimidin and pleiadene derivatives. Tetrahedron 60(17):3797-3802

113. Maloshitskaya O, Jarisinkkonen OVV, Zelenin KN, Pihlajaa K (2004) Chain-ring-chain tautomerism in 2-aryl-substituted hexahydropyrimidines and $1 H$-2,3-dihydroperimidines. Does it appear? Tetrahedron 60(32):6913-6921 
114. Akita M, Seto H, Aoyama R, Kimura J, Kobayashi K (2012) Novel rearrangements in the reactions directed toward preparation of spiro- $N, N$-ketals: reactions of naphthalene-1,8-diamine with ninhydrin and isatin. Molecules 17(12):13879-13890

115. Harry NA, Radhika S, Neetha M, Anilkumar G (2020) A novel catalyst-free mechanochemical protocol for the synthesis of 2,3-di hydro-1 $H$-perimidines. J Heterocycl Chem 57(4):2037-2043

116. Hajra S, Roy SS, Aziz SM, Das D (2017) Catalyst-free "on-water" regio- and stereospecific ringopening of spiroaziridine oxindole: enantiopure synthesis of unsymmetrical 3,3'-bisindoles. Org Lett 19(15):4082-4085

117. Harry NA, Cherian RM, Radhika S, Anilkumar G (2019) A novel catalyst-free, eco-friendly, on water protocol for the synthesis of 2,3-dihydro-1h-perimidines. Tetrahedron Lett 60(33):150946

118. Shaabani A, Hooshmand SE (2017) Diversity-oriented catalyst-free synthesis of pseudopeptides containing rhodanine scaffolds via a one-pot sequential isocyanide-based six-component reactions in water using ultrasound irradiation. Ultrason Sonochem 40(Pt A):84-90

119. Krishna MH, Thriveni $\mathrm{P}$ (2016) A green alternative approach for synthesis of 2-substituted-1H-perimidine catalysed by NBS in ultrasonication method. J Chem Pharma Res 8(4):809-814

120. Hejazifar M, Earle M, Seddon KR, Weber S, Zirbs R, Bica K (2016) Ionic liquid-based microemulsions in catalysis. J Org Chem 81(24):12332-12339

121. Bahrami K, Saleh S (2015) [BTBA]Cl-FeCl 3 as an efficient Lewis acid ionic liquid for the synthesis of perimidine derivatives. Synth React Inorg Metal 46(6):852-856

122. Wasulko W, Noble AC, Popp FD (1966) Synthesis of potential antineoplastic agents. XIV. Some 2-substituted 2,3-dihydro-1H-perimidines. J Med Chem 9(4):599-601

123. Herbert JM, Woodgate PD, Denny WA (1987) Potential antitumor agents. 53. Synthesis, DNA binding properties, and biological activity of perimidines designed as "minimal" DNA-intercalating agents. J Med Chem 30(11):2081-2086

124. Braña MF, Garrido M, Rodriguez ML, Morcillo MJ, Alvarez Y, Valladares Y, Klebe G (1990) Synthesis, structure and cytostatic activity of a series of 2-substituted perimidines. Eur J Med Chem 25(3):209-215

125. Luthin DR, Rabinovich AK, Bhumralkar DR, Youngblood KL, Bychowski RA, Dhanoa DS, May JM (1999) Synthesis and biological activity of oxo-7H-benzo[e]perimidine-4-carboxylic acid derivatives as potent, nonpeptide corticotropin-releasing factor (CRF) receptor antagonists. Bioorg Med Chem Lett 9(5):765-770

126. Dzieduszycka M, Martelli S, Arciemiuk M, Bontemps-Gracz MM, Kupiec A, Borowski E (2002) Effect of modification of 6-[(aminoalkyl)amino]-7H-benzo[e]-perimidin-7-ones on their cytotoxic activity toward sensitive and multidrug resistant tumor cell lines. Synthesis and biological evaluation. Bioorg Med Chem 10(4):1025-1035

127. Arya K, Dandia A (2007) Regioselective synthesis of biologically important scaffold spiro [indoleperimidines]: an antitumor agents. Lett Org Chem 4(5):378-383

128. Farghaly TA, Mahmoud HK (2013) Synthesis, tautomeric structures, and antitumor activity of new perimidines. Arch Pharm Chem Life Sci 346:392-402

129. Azam M, Warad I, Al-Resayes SI, Alzaqri N, Khan MR, Pallepogu R, Dwivedi S, Musarrat J, Shakir M (2013) Synthesis and structural characterization of Pd(II) complexes derived from perimidine ligand and their in vitro antimicrobial studies. J Mol Struct 1047:48-54

130. Farghaly TA, Abbas EMH, Dawood KM, El-Naggar TBA (2014) Synthesis of 2-phenylazonaphtho[1,8-ef][1,4]diazepines and 9-(3-arylhydrazono)pyrrolo[1,2-a]perimidines as antitumor agents. Molecules 19(1):740-755

131. Menteşe E, Yılmaz F, Karaali N, Ülker S, Kahveci B (2014) Rapid synthesis and lipase inhibition activity of some new benzimidazole and perimidine derivatives. Russ J Bioorg Chem 40(3):336-342

132. Alam M, Lee DU (2016) synthesis, spectroscopic and computational studies of 2-(thiophen-2-yl)2,3-dihydro-1h-perimidine: an enzymes inhibition study. Comput Biol Chem 64:185-201

133. Zhang HJ, Wang XZ, Cao Q, Gong GH, Quan ZS (2017) Design, synthesis, anti-inflammatory activity, and molecular docking studies of perimidine derivatives containing triazole. Bioorg Med Chem Lett 27(18):4409-4414

134. Melha SA (2018) Confirmed mechanism for 1,8-diaminonaphthalene and ethyl aroylpyrovate derivatives reaction, DFT/B3LYP, and antimicrobial activity of the products. J Chem 4086824. https://doi.org/10.1155/2018/4086824

135. Kumar A, Banerjee S, Roy P, Sondhi SM, Sharma A (2017) Solvent-free synthesis and anticancer activity evaluation of benzimidazole and perimidine derivatives. Mol Divers 22(1):113-127 
136. Eldeab HA, Eweas AF (2018) A greener approach synthesis and docking studies of perimidine derivatives as potential anticancer agents. J Heterocycl Chem 55(2):431-439

137. Masaret GS, Farghaly TA (2018) Synthesis of 8,10-disubstituted-triazoloperimidines from (e)-3(dimethylamino)-1-(8-phenyl-8h-[1,2,4]triazolo[4,3-a]perimidin-10-yl)prop-2-en-1-one and their antimicrobial activity. Curr Org Synt 15(1):126-136

138. Zhou DC, Lu YT, Mai YW, Zhang C, Xia J, Yao PF, Wang HG, Huang SL, Huang ZS (2019) Design, synthesis and biological evaluation of novel perimidine o-quinone derivatives as non-intercalative topoisomerase II catalytic inhibitors. Bioorg Chem 91:103131-103142

139. Molina P, Alias A, Balado A, Arques A (1994) Iminophosphorane-mediated synthesis of fused perimidines: preparation of quinazolino[3,4-a]perimidine derivatives. Liebigs Ann Chem 7:745-749

140. Panchasara DR, Pande S (2009) Synthesis and biological activity of 3-chloro-1-(4-perimidine methylcarbonyl amino)-4-phenyl-azetidin-2-one. J Chem 6(6). https://doi.org/10.1155/2009/45716 8

141. Üngören SH, Koca İ, Yilmaz F (2011) Preparation of perinones via a novel multicomponent synthesis of isoindole scaffold. Tetrahedron 67(30):5409-5414

142. Chen WZ, Wei HY, Yang DY (2013) Visible light-sensitive properties of 1,2 -dimethyl-2-(2-nitrophenyl )-2,3-dihydro-1H-perimidine. Tetrahedron 69(13):2775-2781

143. Wu CK, Liou TJ, Wei HY, Tsai PS, Yang DY (2014) Visible light photoredox catalysis: aerobic oxidation of perimidines to perimidinones. Tetrahedron 70(44):8219-8225

144. Farghaly TA, Mahmoud HK (2014) Site- and regioselectivity of the reaction of hydrazonoyl chlorides with perimidine ketene aminal. Antimicrobial evaluation of the products. J Heterocycl Chem 52(1):86-91

145. Farghaly TA, Abdallah MA, Muhammad ZA (2015) New 2-heterocyclic perimidines: synthesis and antimicrobial activity. Res Chem Intermed 41:3937-3947

146. Shawali AS, Farghaly TA, Nawar TMS (2016) Chemoselectivity in reactions of hydrazonoyl halides with ethyl 2(3H)-permidinylideneacetate. J Heterocycl Chem 53(3):909-914

147. Koca İ, Böyükata M, Cinaklı S, Oruç Y, Üngören SH (2016) Spectroscopic and structural study of the newly synthesized pyrrolo [1,2-a]perimidin-10-one derivatives. Org Commun 9(4):108-118

148. Baranov DS, Fadeev DS (2016) Synthesis of 2-octyloxy-7H-benzo[ $e]$ perimidin-7-oneand 3-substituted $3 H$-benzo[e]perimidine-2,7-diones. Mendeleev Commun 26(2):174-176

149. Filatova EA, Gulevskaya AV, Pozharskii AF, Ozeryanskii VA (2016) Synthesis and some properties of alkynyl derivatives of 1,3-dialkylperimid ones. An example of the 1,2-palladium migration in the Sonogashira reaction. Tetrahedron 72(12):1547-1557

150. Huang MQ, Liu JQ, Wang XS (2019) Copper-catalyzed synthesis of 13-aminoisoquinolino[2,1a]perimidine-12-carboxylates via $\alpha$-arylation with a high chemoselectivity. J Heterocycl Chem 56(2):663-669

151. Del Valle JC, Catalán J, Foces-Foces C, Llamas-Saiz AL, Elguero J, Sanz D, Dotor J, Claramunt RM (1997) Photophysics of the 2-(2'-hydroxyphenyl)perimidines: photostability studies. J Lumin 75(1):17-26

152. Kim SH, Kim JH, Cui JZ, Gal YS, Jin SH, Koh K (2002) Absorption spectra, aggregation and photo fading behaviour of near-infrared absorbing squarylium dyes containing perimidine moiety. Dye Pigm 55(1):1-7

153. Davis R, Tamaoki NB (2007) Modulation of unconventional fluorescence of novel photochromic perimidine spirodimers. Chem Eur J 13(2):626-631

154. Varsha G, Arun V, Robinson PP, Sebastian M, Varghese D, Leeju P, Jayachandran VP, Yusuff KKM (2010) Two new fluorescent heterocyclic perimidines: first syntheses, crystal structure, and spectral characterization. Tetrahedron Lett 51(16):2174-2177

155. Mahapatra AK, Maji R, Maiti K, Manna SK, Mondal S, Mukhopadhyay CD, Goswami S, Sarkar D, Mondal TK, Quah CK, Fun HK (2014) Synthesis and anion sensing properties of novel N, O-chelated perimidine-BF complex. Sens Actuat B Chem 207(Pt A):878-886

156. Pandian TS, Srinivasadesikan V, Lin MC, Kang J (2015) Nitrite selective anion receptor based on 1-methyl-1H-perimidine. Tetrahedron 71(40):7782-7788

157. Roy D, Chakraborty A, Ghosh R (2017) Perimidine based selective colorimetric and fluorescent turn-off chemosensor of aqueous $\mathrm{Cu}^{2+}$ : studies on its antioxidant property along with its interaction with calf thymus-DNA. RSC Adv 7(64):40563-40570

158. He X, Mao J, Ma Q, Tang Y (2018) Corrosion inhibition of perimidine derivatives for mild steel in acidic media: electrochemical and computational studies. J Mol Liq 269:260-268 
159. Lam RH, McQueen CMA, Pernik I, McBurney RT, Hill AF, Messerle BA (2018) Selective formylation or methylation of amines using carbon dioxide catalysed by a rhodium perimidine-based NHC complex. Green Chem 21(3):538-549

160. Chakraborty N, Banik S, Chakraborty A, Bhattachary SK, Das S (2019) Synthesis of a novel pyrene derived perimidine and exploration of its aggregation induced emission, aqueous copper ion sensing, effective antioxidant and BSA interaction properties. J Photochem Photobiol A 377:236-246

Publisher's Note Springer Nature remains neutral with regard to jurisdictional claims in published maps and institutional affiliations. 